دورية علمية محكمةـ كلية الآداب- جامعة أسوان أبريل 1 ـ ب

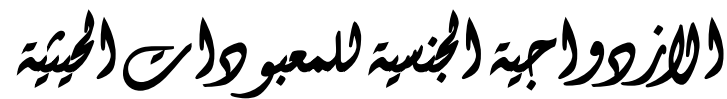

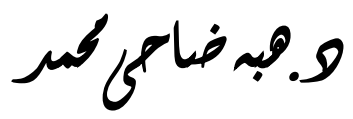




\section{الازدواجية الجنسية للمعبودات الحيثية}

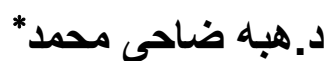

\section{*ملخص البحث:}

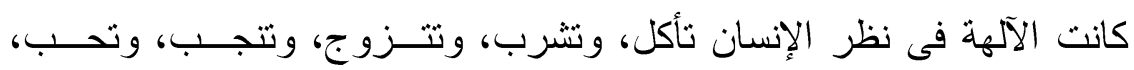

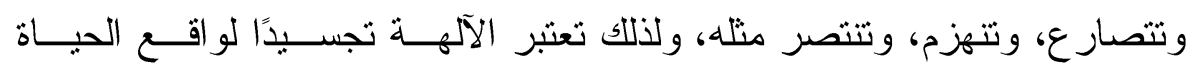
البشرية، و أن كل ما بطر أ على المجنمع البشري من تطور ات في جو انبه الدينيــة و السياسية والاجتماعية ينعكس ذلك بدوره على النظام الإلهى القائم، فمكانة الآلهة و أهميتها، وتغير نوع جنسها، و علاقتها ببعضها تتغير تبعًا لهذه التطور ات.

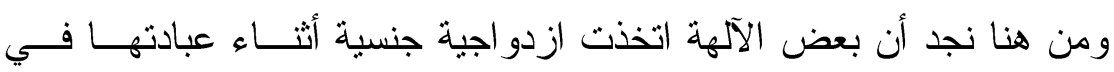
المجتمع الحيثي؛ نتيجة لأســباب دينيــة وتطــور ات فــي الجوانــب السياســية، و الاجتماعية لهذا المجنمع، ولهذا يهدف البحث إلى إلقاء الضوء على هذه الآلهــة،

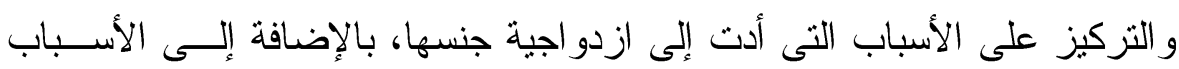
التي أدت إلى تغير نوع جنس بعضها. وقد يكون التغير ليس في نوع الجنس و السمات الخاصة بالإله؛ ولكن قد يكون التغير في الدور نفسه الذي يقوم به، فقد يتغير دور بعض الإلهات وتتخــذ الـدور القيادى الذي يجسده ويمثلك الجنس الآخر وهو مايتم تحليله في هذا البحث. الكلمات المفتاحبة:الحيثيون- الآلهة- إله/إلهة الشمس- الإلهة شاوشجا /عشتار - الإله لاما- الإلهــة

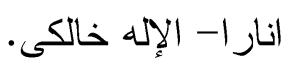




\section{Abstract:}

\section{The Hittites' Gods Dual Sexuality}

The gods in the eyes of man were just like humans eat, drink, marry, and give birth, and love, and wrestling, and defeated, therefore, the gods are considered embodiment of the reality of human life, and all human, political, and social developments in the human society are reflected, in turn, in the existing divine order, the status and significance of the gods, their gender, and their relationship to each other vary according to these developments.

Hence, we find that some gods took dual sexuality during their worship in the Hittite community because of religious reasons and developments in the political and social aspects of this society, so the research aims to shed light on these gods, and focus on the reasons that led to the duplication of sex, in addition to the reasons that led to the change of the sex of some of them.

The change may not be in the gender and attributes of God; however, the change may be in the role it plays; the role of some goddesses may change and take the leading role that is embodied and represented by the opposite sex which is to be analyzed in this research.

key words:-

The Hittites - The Gods - God / The Goddess of the Sun - The Goddess Shaoshaga / Ishtar - God Lama - The Goddess Anara - God Khalki 
تمكن الحيثيون خلال الألف الثاني قبل الميلاد من السيطرة على جزء كبيـر مـن

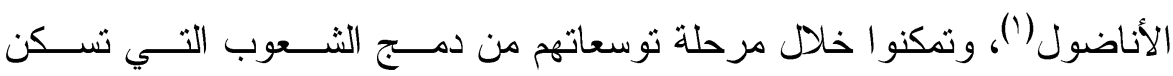

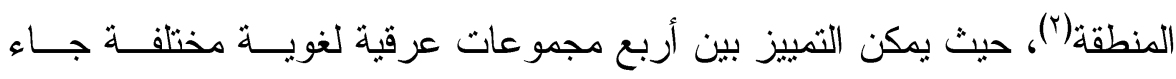

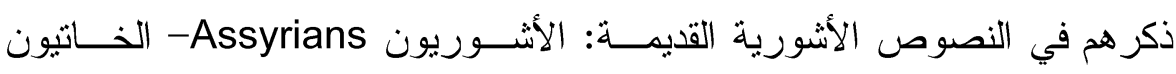

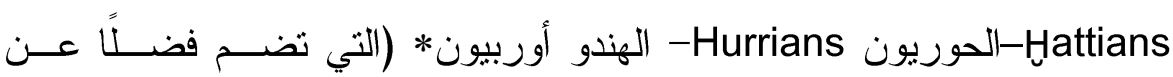

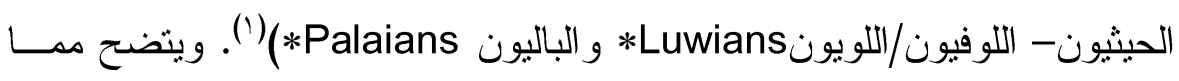

${ }^{(1)}$ Leeming, D.,Creation myths of the world: An Encyclopedia. Vol.1, parts I-II, Oxford, 2010, p.39.

(2) Jones, L., Encyclopedia of religion, vol.6, 2005, p.3595.

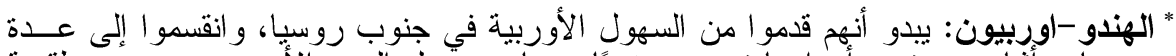

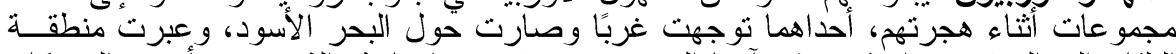

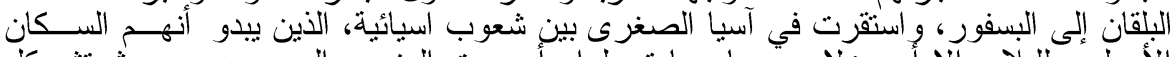

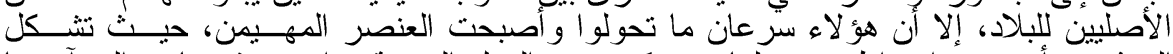

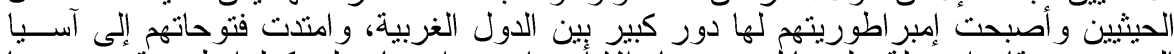

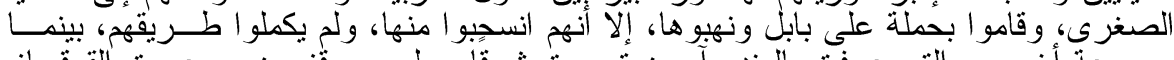

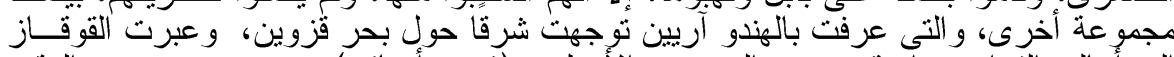

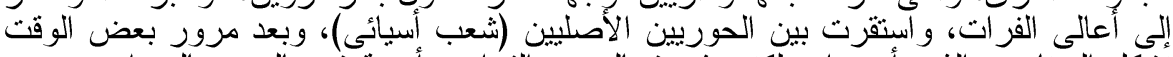

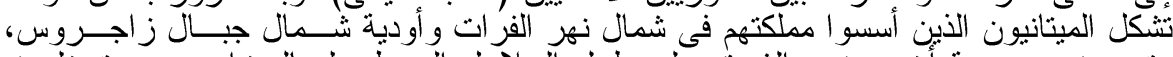

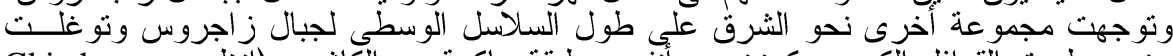

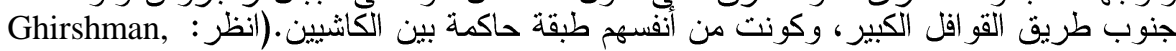
R., Iran from the earliest times to the Islami conquest, Translated from the French by Miss Margared Mum-Rankin, (Pelican books), London, 1978,p.61f. )

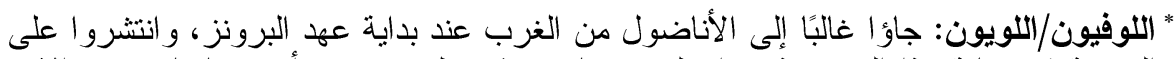

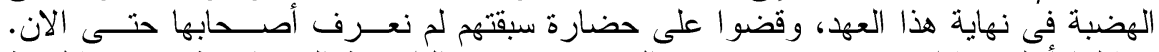

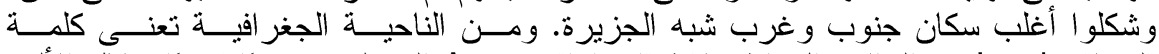

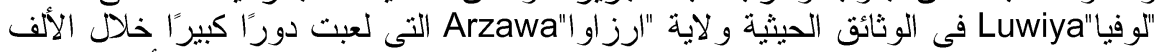

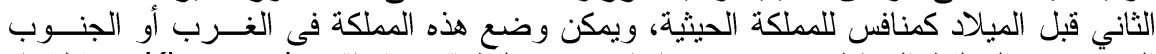

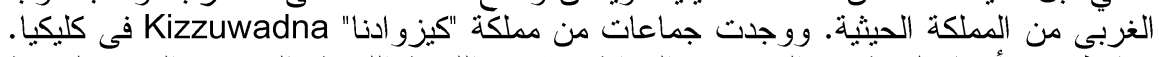

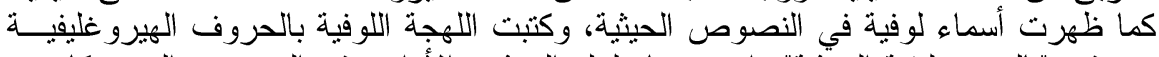

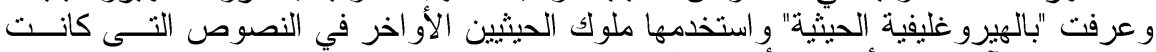

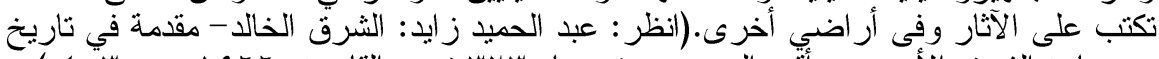

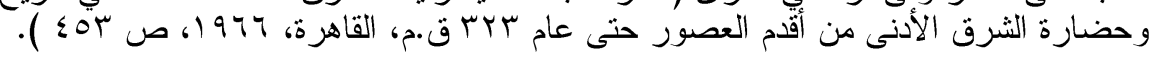

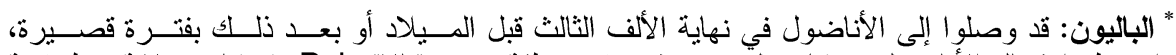

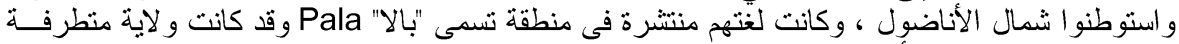

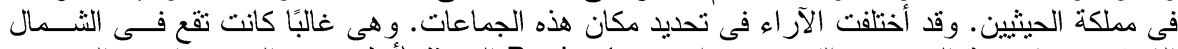

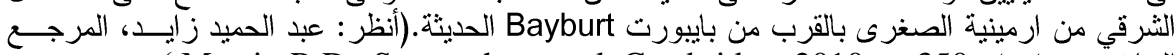

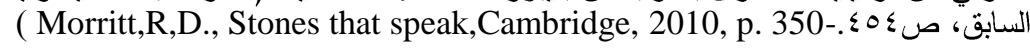


سبق أن الحيثيين حكمو اخليطًا من الشعوب قد جاءت من بلاد النهرين وســوريا، ونقلو ا معهم دياناتهم، وتأثز الحيثيون حضاريًا بتلك البلاد.

وبطبيعة الحال، جميع هذه الثعوب التي استمد الحيثيون منهم حضارتهم كان لايهر طقوس دينية خاصة بهم، هذا بالإضافة إلى آلهتهم التي ظهرت في السجلات الملكية الحيثية (ب).

وكان للآلهة الخاتية دورًا كبيرًا في النظام الديني الحيثي، وتمركزت في مــدينتى "نيريك" Nerik، وخاتوشام Hattuša و اتخذت منهما مر اكز للعبادة خلال فتــرة مبكرة من المملكة الحيثية، ثم انضم إليهم المزيد من الآلهة الجديدة مسـن منــاطق جنوب وشرق المملكة الحيثية(r).

فأصبح النظام الديني الحيثي مكون من خليط من الأنظمة الدينيـــة الأجنبيـــة،

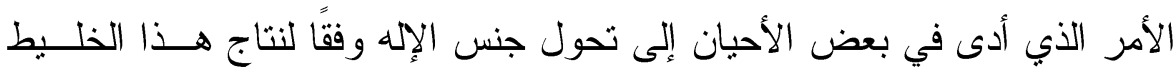

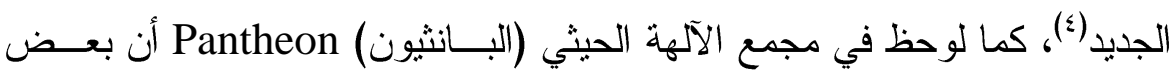

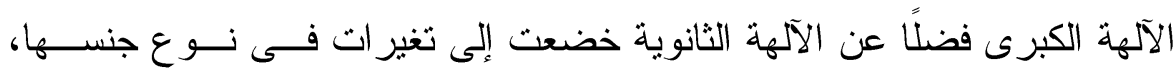

${ }^{(1)}$ Collins, B, J., The Hittites and ther world, Atlanta, 2007, p. 30f .

${ }^{(2)}$ Beckman, G.,"The religion of the Hittites". In, BA, Vol. 52, No. 2/ 3,1989, p. 99.\& Jones, L., op.cit, p.3595.

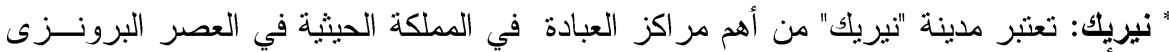

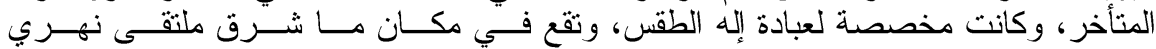

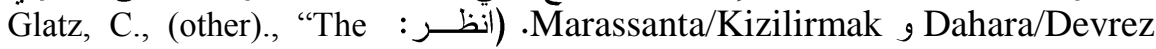
historical geography of north-central Anatolia in the Hittite period: texts and archaeology in concexrt", In, $\boldsymbol{A S}$, Vol.59, 2009, p.68., Bryce, T., The routledge handbook of the peoples and places ancient westrn Asia, the near wast from the early bronze age to the fall of the Persian empire, New York, 2009, p. 506.)

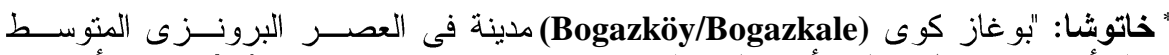

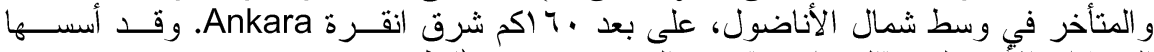

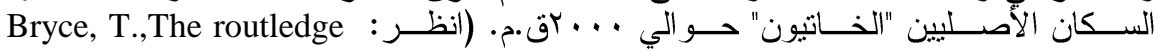
handbook of the peoples and places, p.298.)

${ }^{(3)}$ Beckman, G.,"The religion of the Hittites", p.99.

(4) Jones, L.,op.cit, p.3595. 


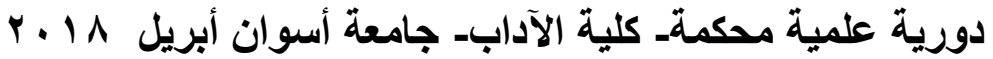

و التي يمكن تفسيرها أو اعتبارها رمزًا للتغيرات السياسـية و الاجتماعيــة التــي طر أت على المجتمع الحيثي" (') ويسلط هذا البحث الضوء علــى تلــــ الظـاهرة بمزيد من التقصيل و التحليل، وذلك من خلال تتاول هذه الآلهة التى لها ازدو اجيــة جنسية، و الآلهة التى تحولت جنسيًا مع ذكر الأسباب التى أدت إلى ذلك كما يلي:

\section{أولاًِ- إله/| إلهِة (لشمس):-}

أطلق السومريون على إله الشمس اسم "اوثو" ومعناه الضوءء، و النور ، و اليــوم، وكذلك الصفة "ناصع"، كما أطلقو ا عليه أيضًا "يبار" أى المنير"، وهو ثقريبًا نسخة

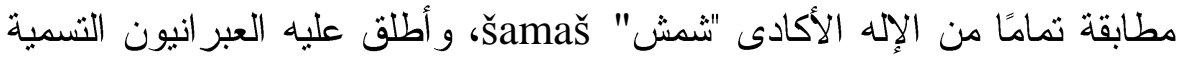

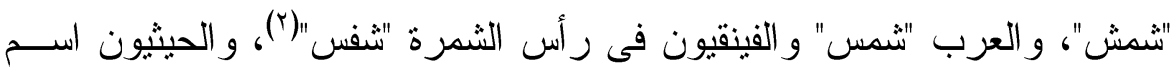

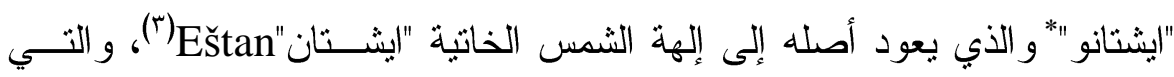

${ }^{(1)}$ Lerner, G., The creation of patriarchy, Oxford, 1986, p. 157.

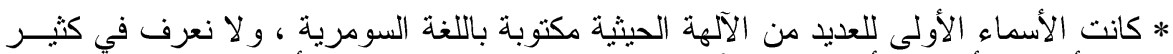

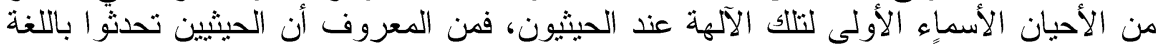

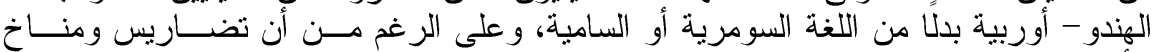

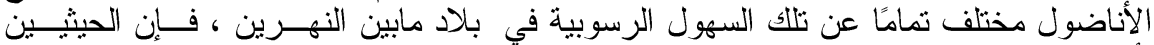

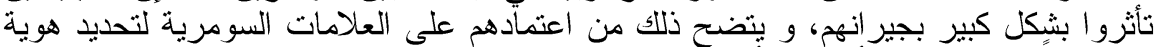

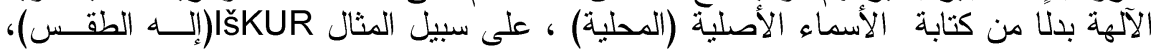
UTU الرئيسى في أن الأسماء الأصلية للعديد من الآلهة الحيثية غير معروفة اليوم.(انظر : Allen, S., The Splintered Divine, A Study of Ištar, Baal, and Yahweh Divine Names and Divine Multiplicity in the Ancient Near East, Berlin, 2015, p.71.)

$$
\begin{aligned}
& \text { (r) أحمد أمين سليم: در اسات في تاريخ وحضارة مصر و الثرق الأدنى القديم، حضارة العراق }
\end{aligned}
$$

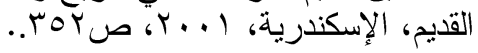

- Gurney, O., Some aspects of Hittite religion, Oxford, 1977, p.11.

"يظهر ايشتانو في صلاة Kantuzzili (أمير ملكي من المحتمل أن أبيه مورشيلي الثاني وأخيـهـ

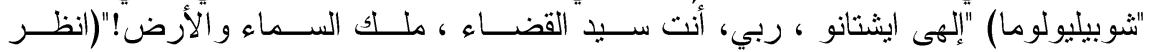

Güterbock, H., "The composition of Hittite prayers to the sun”, In, JAOS, vol. :

78, No.4, 1958, p. 240f.)

${ }^{(3)}$ Lerner, G., op. cit, p.157. 


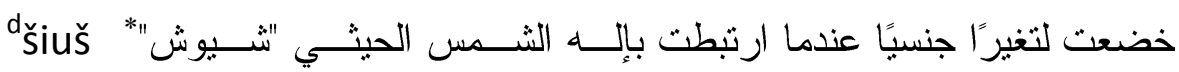

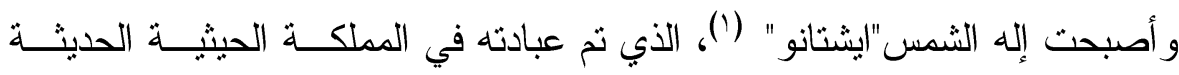

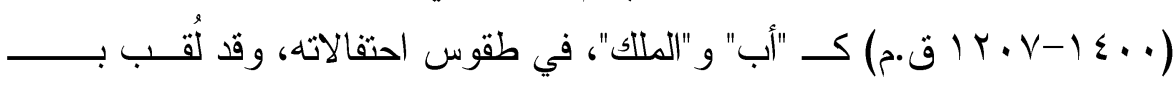

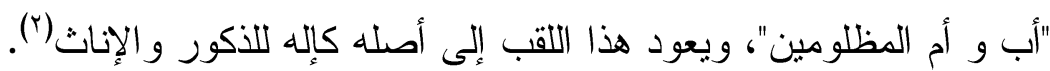

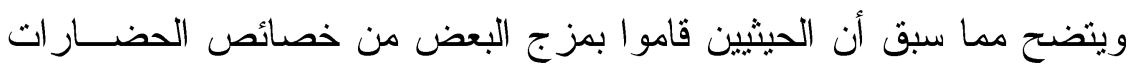

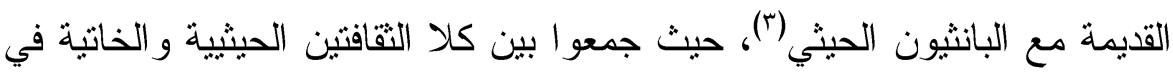

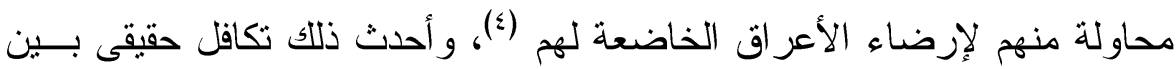
السكان الأصليين و الو افدين الجدد، وخاصة على المستوفى الأثقافى (॰). وتقدم نصوص الصلاة و المعاهدات بشكل كامل البانثيون الحيثي، ويظهر إلــــ

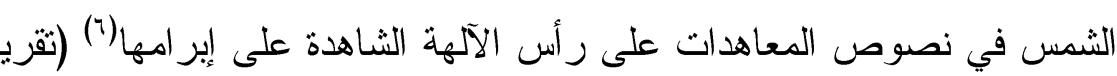

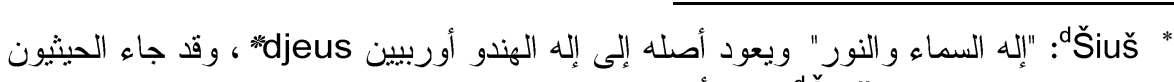

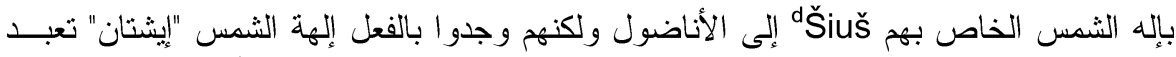

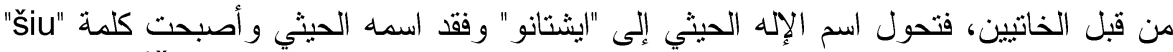

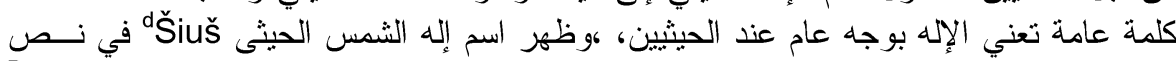

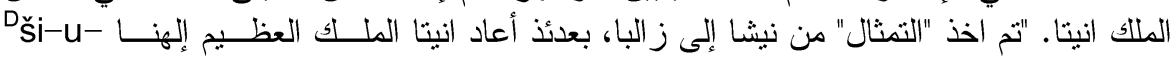

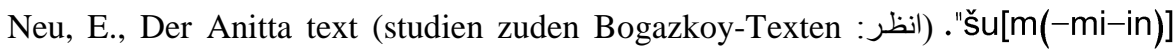
Band.18, Otto Harrassowitz. Wiesbaden, 1974, S.13., Tatišvili, I., "Transformations of the relationship between HittiteKings and deities", published in the Acts of the IXth International Congress of Hittitology,Çorum, P.3., Forsgren, M., "The divine appearance of Harn", current Swedish archeology, vol.18, 2010, p.114.)

${ }^{(1)}$ McGrath, S., "The hidden Sun", In. Drawing own the Sun : Rekindle the Magick of the Solar Goddesses, Edit by Woodfield, S., Woodbury, Minnesota, 2014, p.6., Forsgren, M., op.cit, p.114.

${ }^{(2)}$ Lerner, G., op.cit, p. 157.

${ }^{(3)}$ Forsgren, M., op.cit, p.114.

${ }^{(4)}$ Collins, B., op.cit, p.173.\&Lerner, G., op.cit, p.157.

(5) Sánchez, D, (others)., Mediterráneos: An interdisciplinary approach to the cultures of the Mediterranean sea, Cambridge, 2013, p.174.

${ }^{(6)}$ Gurney, O., op.cit, p.11. 


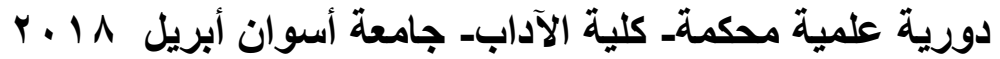

بشكل ثابت) فهو الذي ير أس العدالة الإلهية، و السلوك الصحيح علــى الأرض(')،

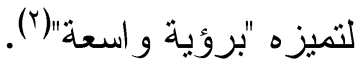

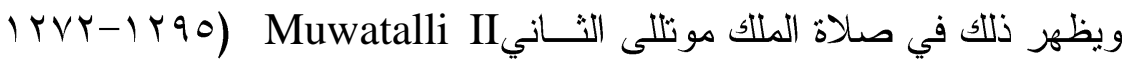

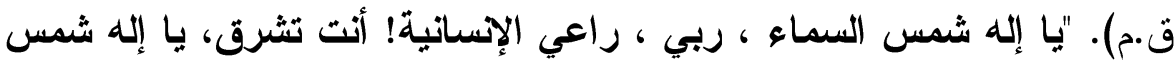

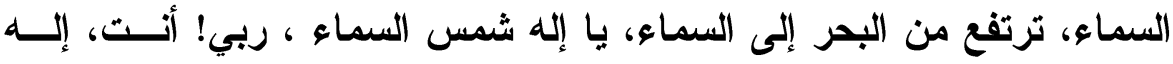
الثمس، إنك تجلس يوميًا لمحاسبة الرجل "الإنسان"، الكلب، الخنزير، وحيوانات

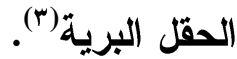

و أطلق الحيثيون على إلهة الثمس اسم "أرينا"* Arrina ، وتمثل أعلى رثبـــة

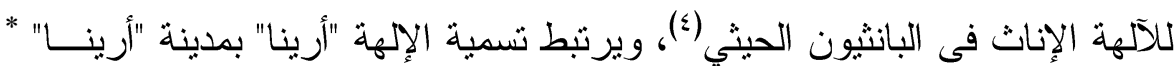

(1) Bryce, T., Life and society in the Hittite world, Oxford, 2002,p. 141.

${ }^{(2)}$ Lerner, G., op.cit, p. 157.

${ }^{(3)}$ Singer, I., Hittite prayers, vol.11, Edited by Hoffner. H, Atlanta, Georgia, 2002, p.91.

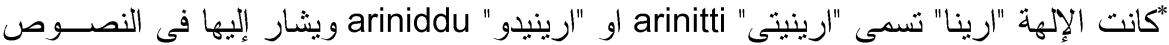

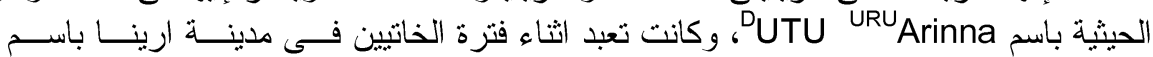

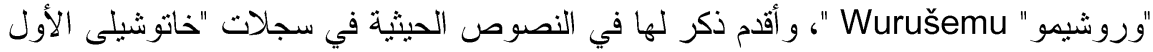
I I Hattušili

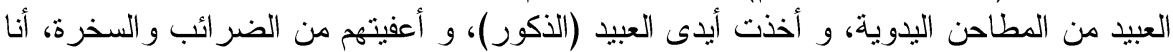

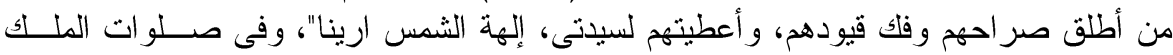

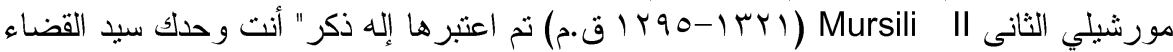
فقط"، وهذا يرجع إلى كونها ملكة السماء و الأرض(انظ (انظر : -Laroche, E., "Hattic Deities and their Epithets", JCS, Vol. 1, No. 3, 1947,p.19. \& Macqueen, J., "Hattian mythology and Hittite monarchy, In, $\boldsymbol{A S}$, vol.9,1959,176. , Güterbock, H., "An addition to the prayer of Muršili to the sungoddess and its implication", $\boldsymbol{A S}$, Vol.30, 1980, p.43., Gurney, O.,op.cit, p.12., Collins, B, J. op.cit, p.92., Bryce, T.,Life and society in the Hittite world,p.143)

${ }^{(4)}$ Sánchez, D,(others)., op.cit,p.175.

"أرينا: أطلق اسم "أرينا" في نهاية العصر البرونزى على العديد من الددن التى تقع في الأناضول

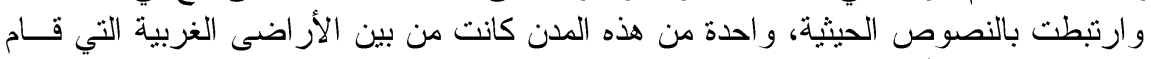

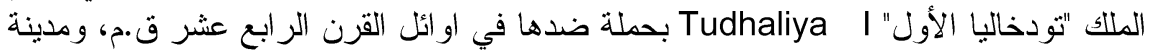

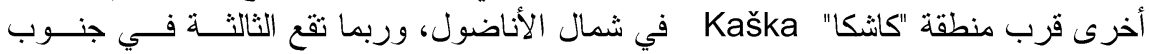


و اعتبرت رفيقة إله- الطقس الخاتي "تارو "Taru (')، كما اعتبرت راعية وحامية

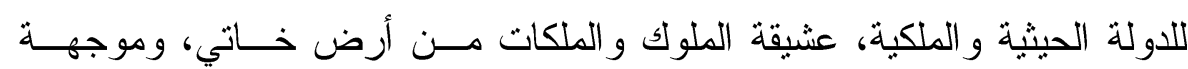
حكو مة الملك و الملكة(؟).

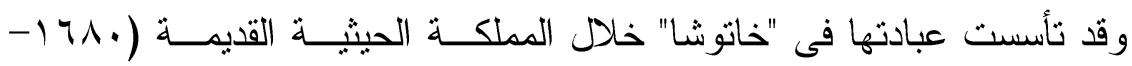

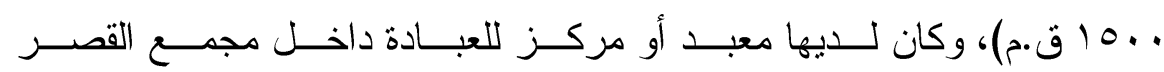
$\cdot^{\left({ }^{\top}\right)}$ Büyükkale

وفيما يلي عرض لأسباب الازدواجية الجنسية لإله/إلهة الشمس عند الحيثيين 1-أسباب دينية للازدواجية الجنسبة لإمه/إلهة الثمس:-

كانت هناك جوانب مزدوجة لدور الإله في الفترة الحيثية، حيث عبرت طبيعة

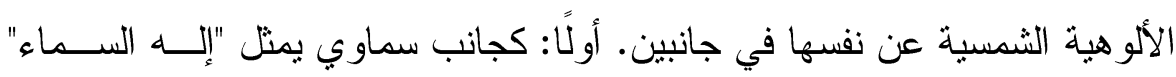

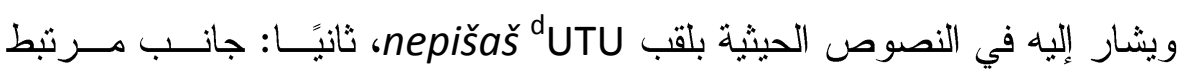

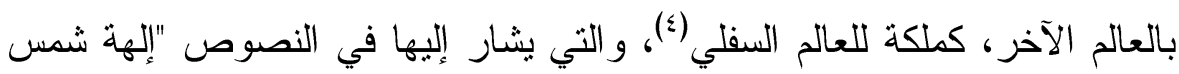

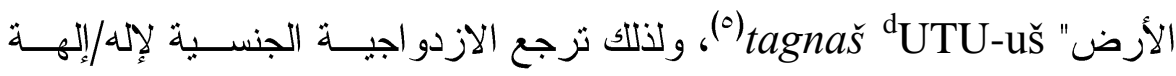

=الأناضول، ولكن أهم مدينة لدى الحيثين و التي كانت مخصصة لعبادة إلهة الثمس، ورفيقها

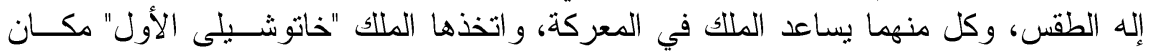

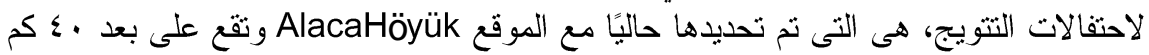

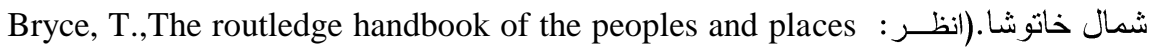
ancient westrn Asia, p. 62., Burney, C., Historical dictionaries of the Hittites, Oxford, 2004, p.28., Haas, V., Geschichte der Hethitischen religion, New York, 1994, p.585.)

${ }^{(1)}$ Bryce, T., Life and society in the Hittite world, p.142.

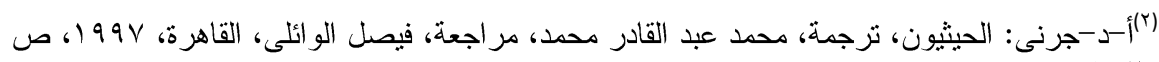
.$I V Y$

(3) Bryce, T.,Life and society in the Hittite world,p.142.

(4) Sánchez, D, op.cit, p.175.

${ }^{(5)}$ Karasu, C., "Why did the Hittites have a thousand deities?", In. Hittite studies in honor of Harry A.Hoffner JR. On the occasion of 65Th birthday. Edited by Beckman.G., (others),Winona, Indiana, 2003, p.231. 


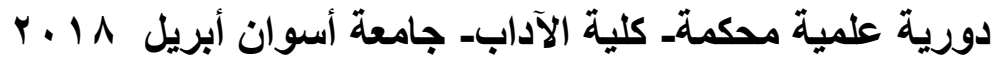

nebiš الثمس إلى أن الحيثيين فسروا مفهوم العالم على إنـــه الســـاء و الأرضـ

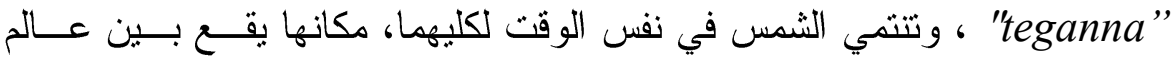

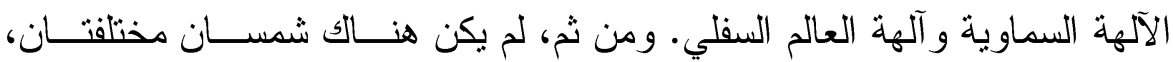

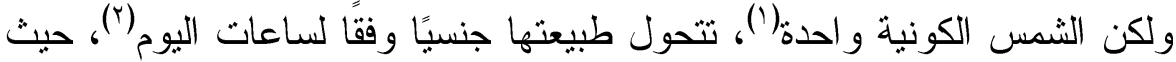
إن الشمس في المساء تنزل تحت الأرض للتجول في العالم السفلي، وفي الصــباح تصعد لتشرق في عالم الدنبا ().

ويظهر في عصر المملكة الحيثية الحديثة إله شمس السماء كإله ذكر، و إلهـــة

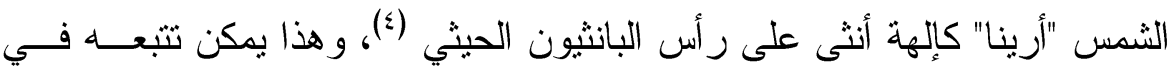

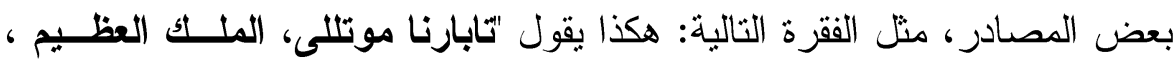

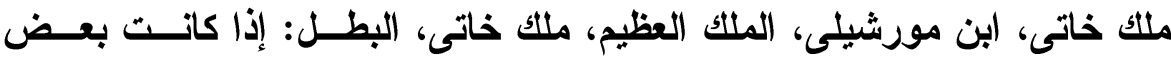
المشاكل تثقل كاهل الإنسان، يجعل نداء إلى الآلهة، يضع على السطح، ويواجـهـ

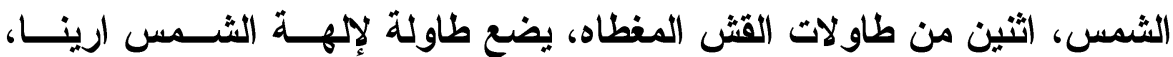

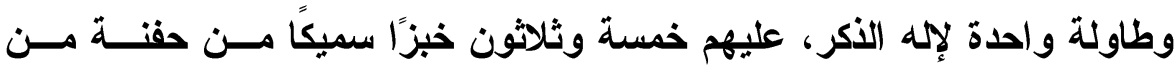

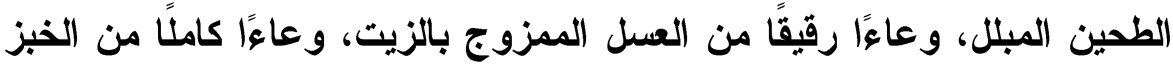

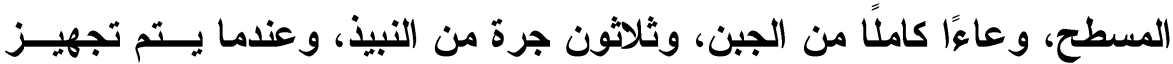

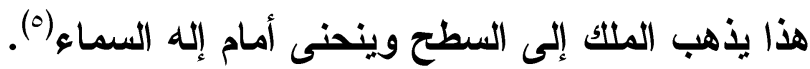

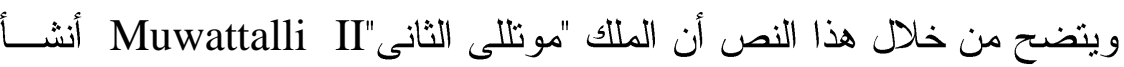
في وقت و احد مائدة قر ابين لإلهة الثمس "ارينا" ووجه كلمة إلى "إله السماء" فى

${ }^{(1)}$ Sánchez, D, op.cit, p.175.

${ }^{(2)}$ Bryce, T., Life and society in the Hittite world, p.142.

(3) Haas, V., op.cit, S. 421.

${ }^{(4)}$ Neu, E.,op.cit, S.127.

${ }^{(5)}$ Belmonte, J. (other)., "Thinking Hattusha: Astronomy and landscape in the Hittite lands". In, JHA, Vol. Xlii, 2011, p.6., Singer, I, op.cit, p.86., Collins, B., op.cit, p.172. 
نفس السياق الطقسى (1).

ويتضـح تصوير الشمس كوحدة كونية و احدة في مقتطف مسـن صــلاة الملكــة

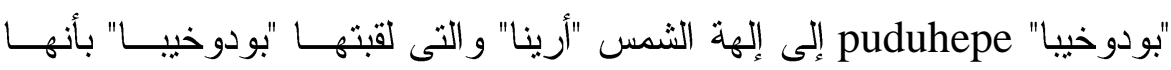
"ملكة السماء و الأرض"(ب).

"إلى إلهة الشمس أرينا ، ســيدتي ، ســيدة أراضــي خـاتي ، ملكـة الســـاء

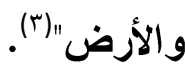

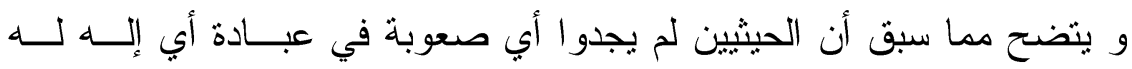

ازدو اجية جنسية؛ لأن هذا الأمر يسمح لهذا الإله أن يقوم بــأدوار مختلفــة فـي

سياقات دينية أكثر (ء).

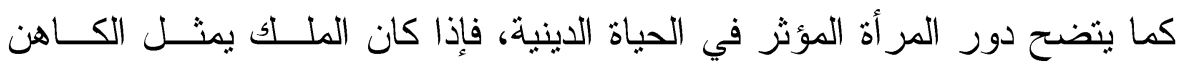
الأعلى للآلهةة(0) كانت الملكة على الجانب الآخر تمثل منصــب رئيســة كهنـة

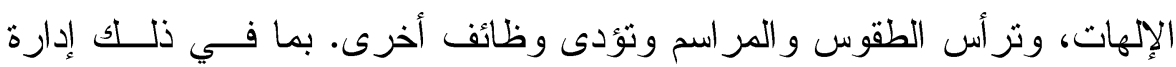
أصول بعض المعابد أو الأوقاف الدينية، وكانت و اجباتها الدينية تجعلهــا نتثــلـ أحيانًا إلى المر اكز الدينية خارج العاصمة على غرار أزو اجهن مــن المـــوك(؟). ولذلك كان من الطبيعي المساو اة بين الرجل و المر أة في المهام الدينية، و انعكـــاس مشاركة المر أة في الأمور الاينية على رثبة الإلهات في البــانثيون الحيثـي. و إذا كان الإله إشتانو من ضمن ألقابه " أب و أم المظلومين" ويشمل لقبه خصـــائص

${ }^{(1)}$ Belmonte, J. (other).,op.cit, p.6.

${ }^{(2)}$ Lerner, G., op.cit,p.158., Sánchez, D,(others)., op.cit,p.175.

${ }^{(3)}$ Singer, I,op.cit, p.102.

(4) Ibid, p.142.

(5) Blasweiler, J., "The Tawananna and the royal succession", In. A paper at the 10th Hittitology Congress in Chicago, University of Chicago,2017, p.6.

${ }^{(6)}$ Marinatos, N., "The minoan harem: The role of eminent women and the knossos frescoes*", DHA, Vol.15-2,1989, p.36., Collins, B., op.cit, p.99. 
الذكر و الأنثى كان لابد لإلهة الشمس أن تجمع نفس الصفات، ولذلك اتخذت لقـب

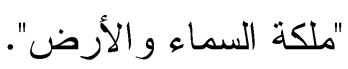

\section{r- أسباب سباسبة واجتماعية للازدواجية الجنسبة لإهة/إلهة الثمس:-}

كانت الآلهة تجسيدًا لحباة الإنسان؛ لذلك وجد الرجل الثبه في الألهة، ووجدت المر أة الثبه في الإلهات(')، ولهذا الأمر قام الحيثيون بربط الملك مع إلــهـ شــس الإسل

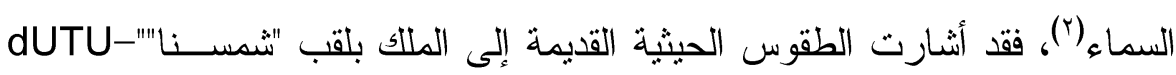

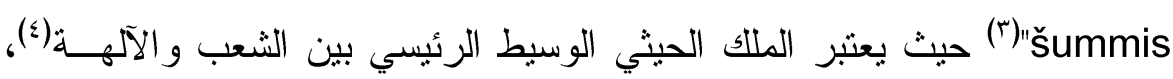
كما حمل الملوك الحيثيون لقب "شمسي" ddUTU-Ši* الذي كان له الأسبقية علـى جميع الألقاب الملكية الأخرى حتى على اللقب "الملك العظيم" "تابار انا/ لابار انــا" Labrana/Tabarna وكان الملك يشار إليه في المعاهدات و المر اسلات الدبلوماسية بلقــب "شمســـا"

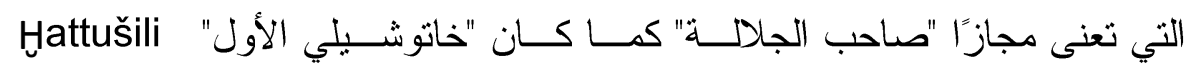

${ }^{(1)}$ Lerner, G., op.cit, p.160.

${ }^{(2)}$ Collins, B., op.cit, p.99., Marinatos, N., "The minoanharem: The role of eminent women and the knossos frescoes*", Dialogues d,histoire ancienne, Vol.15-

2,1989, p. 35 .

${ }^{(3)}$ Daniè le, M., "The royal Hittite title 'My Sun, and the Winged Sun Disk ". In: 38. ICANAS, Religion, vol. 1, International Congress of Asian and North African Studies,Ankara2007,Atatürk Kultür, Dil Ve Tarih Yüsek Kuramu Yaninlari 3/1, Ed. Zeki Dilek et al., Ankara, p.330.

(4) Hoffner, H., The royal cult in Hatti, p.145.

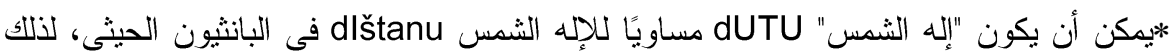

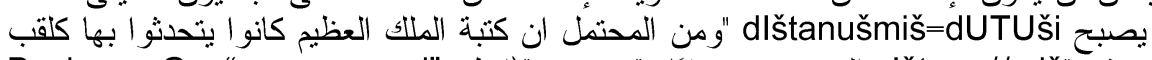

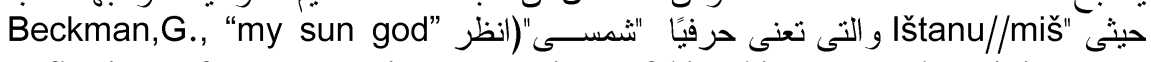
Reflections of Mesopotamian conceptions of kingship among the Hittite*, In,. Ideologies as Intercultural phenomena, Editor. Panaino, A.(other), Melammu Symposia 3. Milano, 2002 p. 37., Bossert. H., "Meine sonne", In.Or NS, vol.26, 1957, P.102.)

${ }^{\left({ }^{\circ}\right.}$ Hoffner, H., The royal cult in Hatti, p.145., Beckman,G., "my sun god",p .37. 


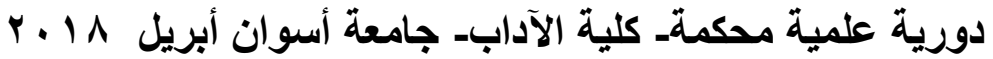

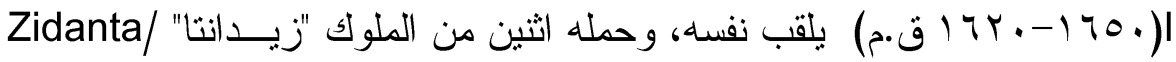
za

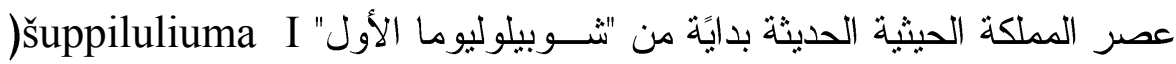

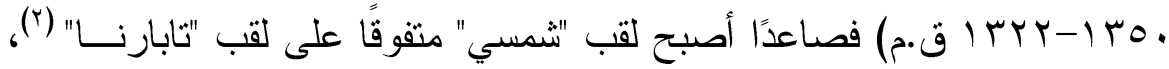

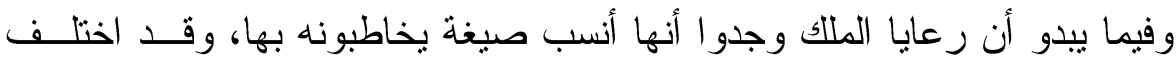

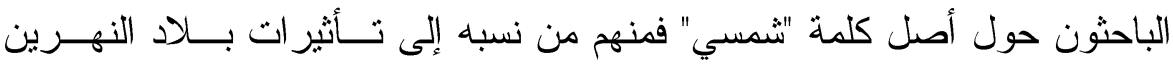

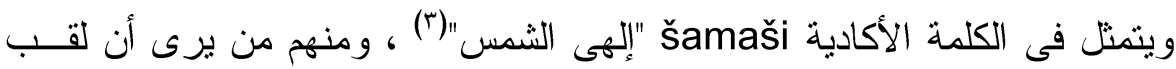

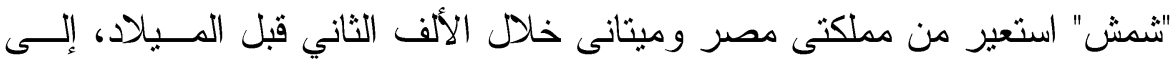

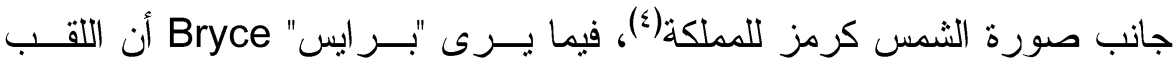
"شمسي" استمد من شمال سوريا وليس من مصر (0).

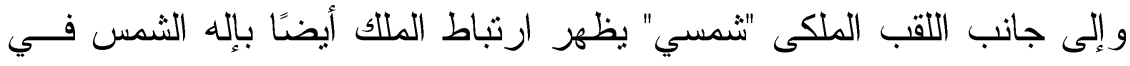

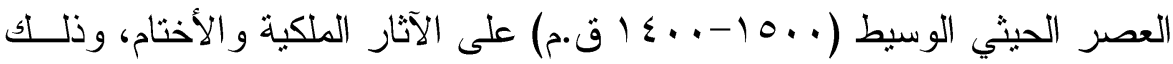
من خلال قرص الشمس الذي يتم وضعه فوق الشخصية الملكية، ثم علــى اســـ

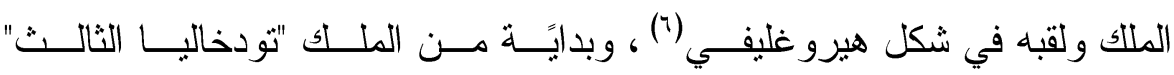
TudhaliyaIII الحماية لإله شمس السماء للملك، ويظهر ذللك في تمثيل قرص شمس مجنح فــوق

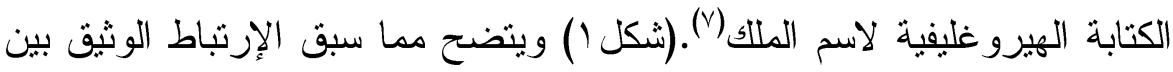

(1) Gonnet, H., "Gonnet née Bagana Hatice. La titulature royale hittite au IIe millénaire av. J.C,EPHE, Vol.80-81, 1971, p.112.

${ }^{(2)}$ Daniè le, M., op.cit, p.329.

${ }^{(3)}$ Hoffner, H., The royal cult in Hatti, p.145., Beckman,G., "my sun god”,p .37.

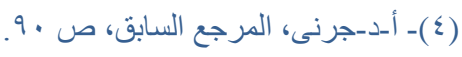

${ }^{(5)}$ Bryce, T, R.,The kingdom of Hittites, Oxford, 2005, p.20.

${ }^{(6)}$ Daniè le, M., op.cit, p.329.

${ }^{(7)}$ Taracha, P.,Religions of second millennium Anatolia, Wiesbaden, 2009, p.90. 
إله الثمس و الملاك، هذا الإزتباط الذى يعبر عن خاصـية إلهيــة متجسـدة فـى

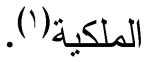
ويظهر ارتباط الملك أكثر بإلّه الشمس و انتماءها إلى العالم الإلهى، وذلـــك مــن

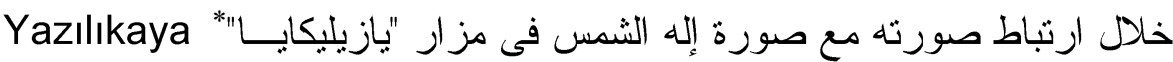

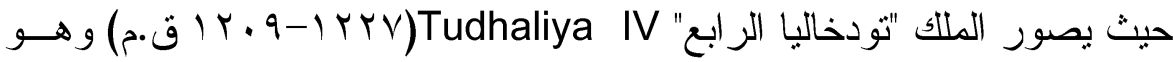

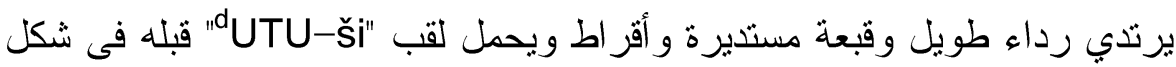

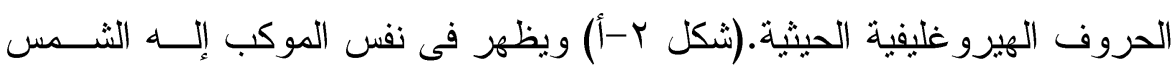

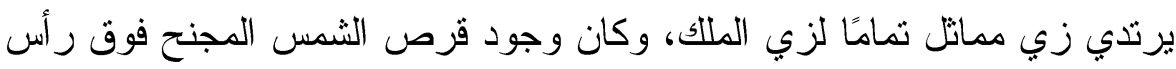

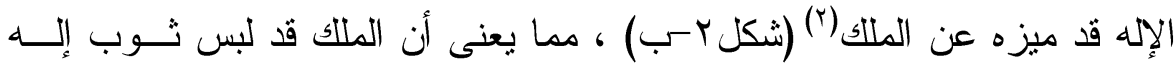
الشمس ولقب بــ"ثمسي"(").

و في مقابل علاقة الملك بإله الثمس، ارتبطت الملكة بإلهة الثمس ويتضح ذلـــك في لقب "الملكة" الذى تحمله كل من "إلهة الشمس" و "تاو انانتــا" Tawananna،

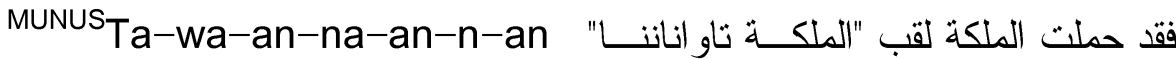

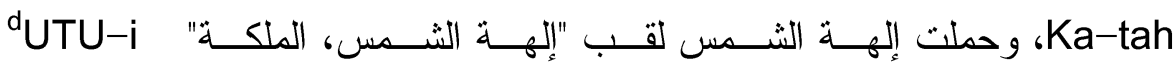
"MUNUSLUGAL. من ذلك أن العلاقة مع تاو انانتا بتمثل العلاقة مع إلهة الثمس نفسهان(ه).

${ }^{(1)}$ Danièle, M., op.cit, p.329.

يقع مزار "يازيليكايا" الصخرى على بعده، أكم إلى الثمال الثرقى من العاصمة الحيثية في "

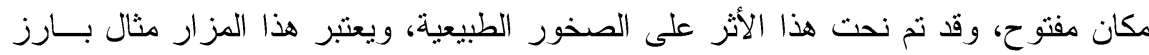
Onurlu, S., Symbol space and meaning in the Hittite architecture, Middle east technical university, Ankara, 2004, p.54f)

(2) Beckman,G., "my sun god", p.40.

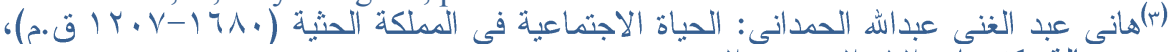

- Tatišvili, I., op.cit, p.4.

${ }^{(4)}$ Blasweiler, J., "The Tawananna and the royal succession",p.6f.

${ }^{(5)}$ Blasweiler, J., The bloodline of the Tawananna and the offering to the ancestors in the kingdom of Hatti, Netherlands, 2016. P.24. 


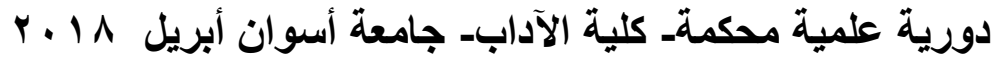

وتميزت أيضًا علاقة الملكة مع إلهة الثمس بالخصوصية في مدينة "أرينا"، فقــــ كانت الملكة بعد وفاتها تمثل في صورة هذه الإلهة في المعبد") و واعتبر الحيثيون

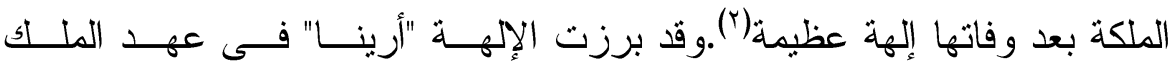
"خانوشيلي الثالث" Hattušili III الفضل في ذلك إلى الملكة "بودوخيبا" Puduhepa التي تضر عت بــالكثير مــن

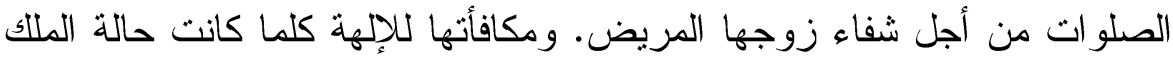

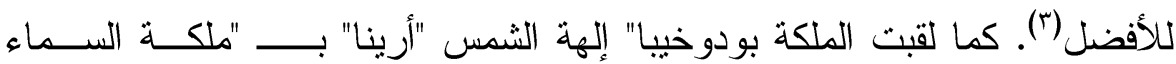
و الأرض" وذلك في الوقت الذي كانت فيه السلطة الذكورية مؤسسة بشكل راســخ بــ

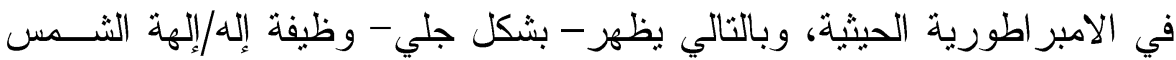

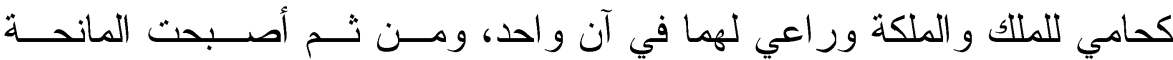
للشر عية الالهية المقدة للسلطة الدنيوية(أ).

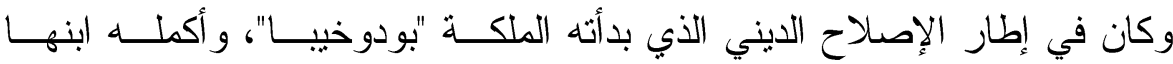
"تودخالبا الر ابع" Tudhaliya IV التوفيق بين المعتقدات و الآلهة الرسمية، وذلك بإعادة هيكلة النظام الديني، وعلى لـى

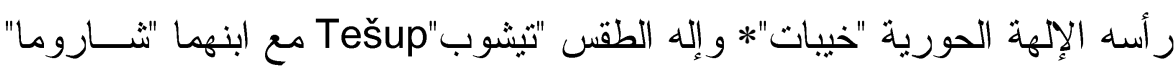
Sharruma

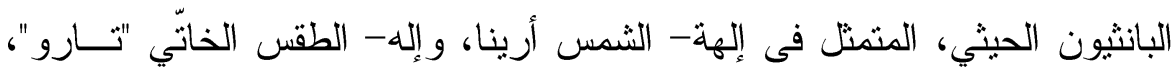

${ }^{(1)}$ Beckman,G., "my sun god, p.40f., Collins, B., op.cit, p.99.

${ }^{(2)}$ Blasweiler, J., The bloodline of the Tawananna, 2016. P.24.

${ }^{(3)}$ Bryce, T.,Life and society in the Hittite world,p.142.

${ }^{(4)}$ Lerner, G., op.cit, p.158..

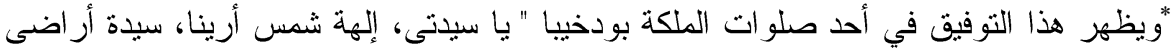

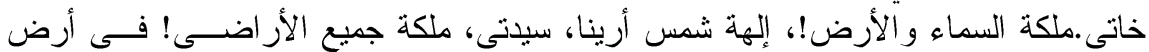

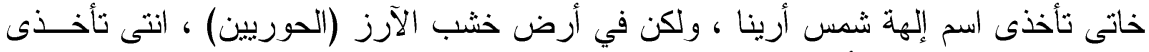

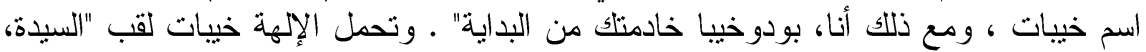
ملكة السماء" (انظر: , Forsgren, M., op.cit, p.116., Jones, L., op.cit, p.3595., Karasu C., op.cit, p.228. ) 


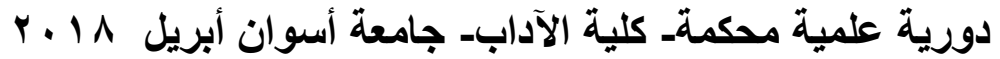

و ابنهم إلهـ- الطقس "تيريكت" Nerik، وتمثل هذا التوفيــق بــين الآلكهـة الحثيـــة

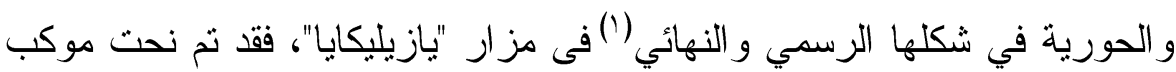

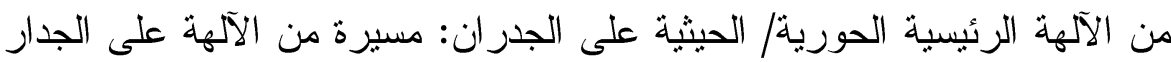

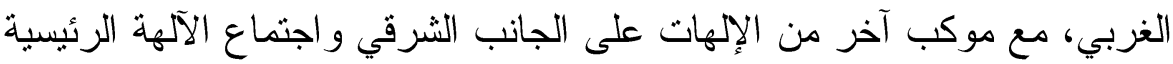

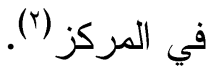

ويؤكد هذا الأثز الصخري التماثل و الأهمية المنســاوية للآلهـــة و الإلهــات(").

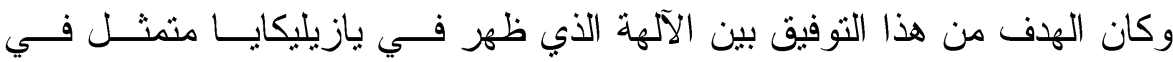

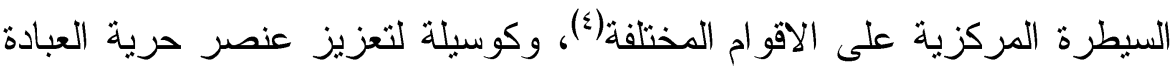
داخل الإمبر اطورية وتشجيع الثماسك الديني و الوحدة السياسية (0).

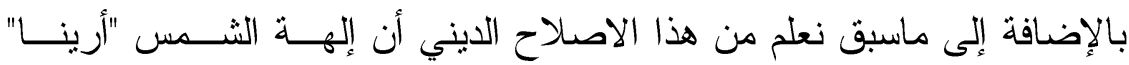

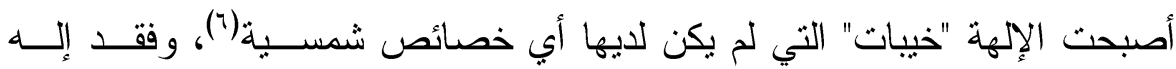
الثمس مكانته ،ويتضح ذللك في موكب الآلهة بمزار "يازيليكايا"، حيث يقف إلــهـ

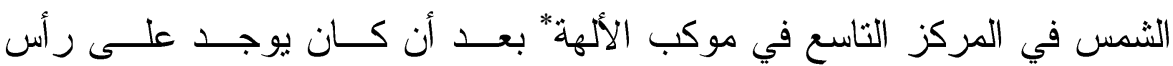

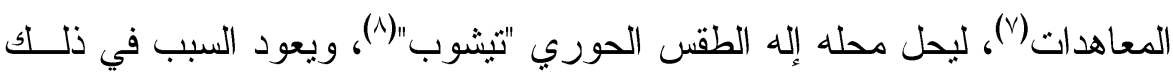

${ }^{(1)}$ Collins, B., op.cit, p.177., Sánchez, D, (others)., op.cit, p.176.

${ }^{(2)}$ Jones, L.,op.cit, p.3595.

${ }^{(3)}$ Ibid, p.3595.

(4) Tatišvili, I., op.cit, p.8.

${ }^{(5)}$ Collins, B., op.cit, p.177.

${ }^{(6)}$ Forsgren, M., op.cit, p.116.

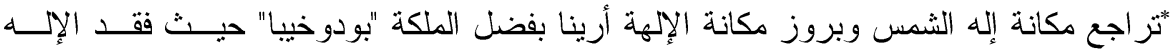

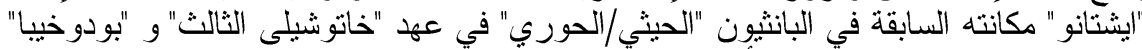

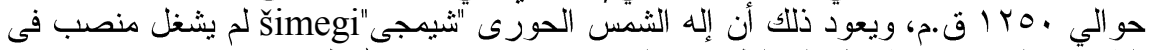

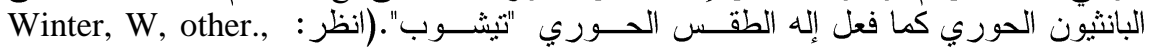
Reconstructing Languages and Cultures, New York, 1992., p.449.)

${ }^{(8)}$ Lerner, G., op.cit, p.158.. 
إلى نفوذ الملكة "بودوخييا" التي جاءت بإلهنها الخاصة "خيبـات" لتكريســها فـي

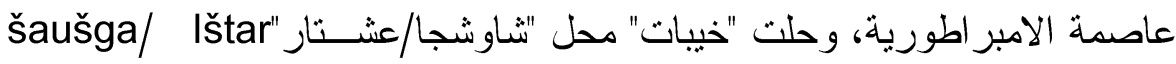

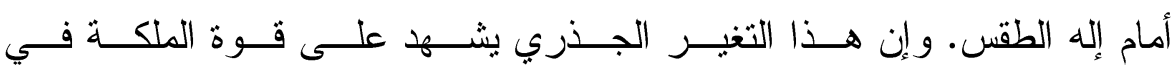

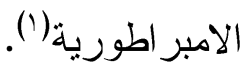

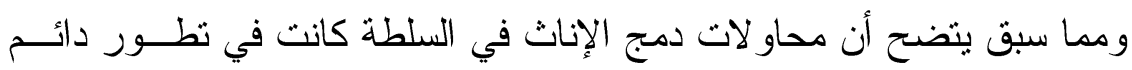
و انعكس ذللك على البانثيون الحيثي؛ لأن وجود الآلهة الإناث في البانثيون الحيثي الإني

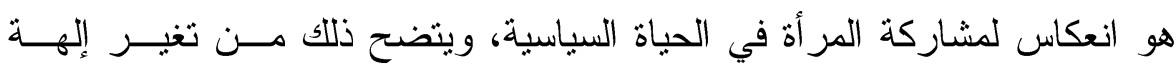

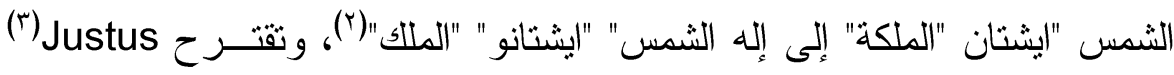
نقلًا عن McGrath : " أن هذه التغيرات التى طر أت في تغير جنس الإله تعكس التس

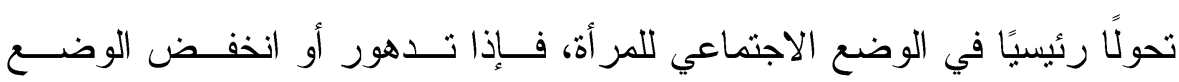

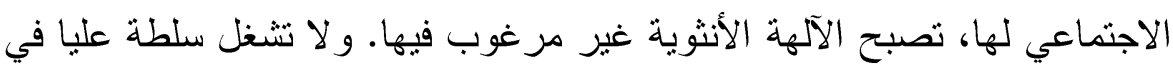

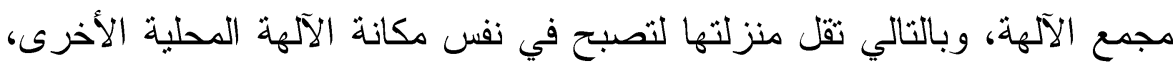

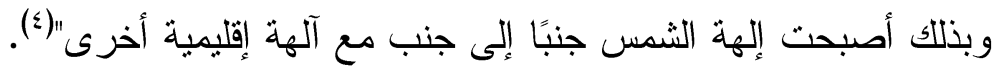

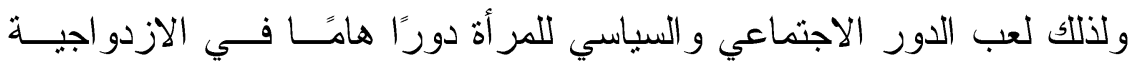

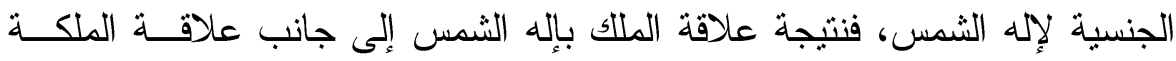

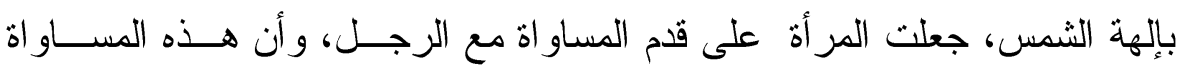
الأساسية لا يمكن نفيها من الفكر و الشعور مادامت الآلهة تعيش ويعتقد أنها تحكم

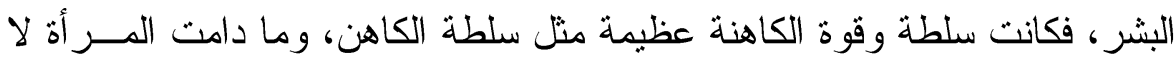

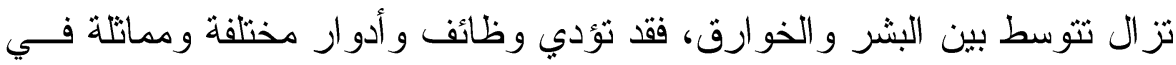

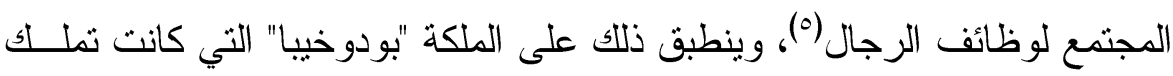

(1) Alexander, R., "Šaušga and the Hittite ivory from Megiddo, In. JNES, Vol.50, No. 3, 1991, p.177.

${ }^{(2)}$ Lerner, G., op.cit, p.158..

${ }^{(3)}$ Carol F. Justus, "Indo-Europeanization of Myth and Syntax in Anatolian Hittite:Dating of Texts as an Index, JIES, vol. 11, 1983, P. 59-103.

${ }^{(4)}$ McGrath, S.,op.cit, p.6.

${ }^{(5)}$ Lerner, G., op.cit, p.160. 


\section{دورية علمية محكمة كلية الآداب- جامعة أسوان أبريل 1 ـ ب}

ختم خاص بها، ويظهر به قرص الشمس المجنح الذي يشير إلى اللقب "شمسـي" (جلالتى) رمز الملكية.(شكل ب) وتعد هذه الأختام التي تحمل اسم الملكـــة دلياً

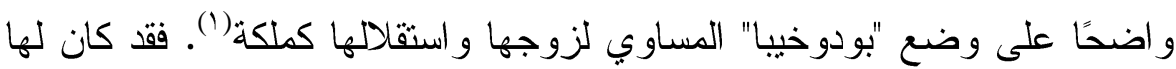
تأثير قوي على زوجها، وحثثه على تضمين آلهة حورية وطقوس دينيــة داخـلـل

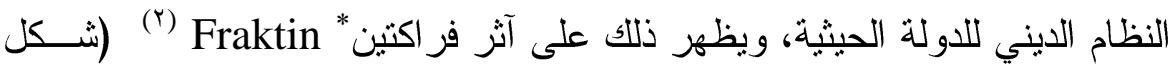
§) بالإضافة إلى مشاركثها في الحياة القضائية، حيث شاركت زوجها في و اجباته

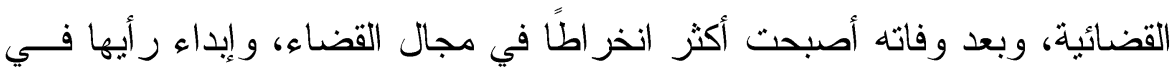
القضايا التي تخص الو لايات التابعة لخاتى، و على الجانب السياسي كان لها تـأثثر

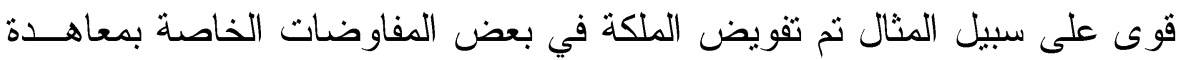
السلام بين مصر لخاتى بسبب مرض زوجها "خاتوشيلي الثالث (").

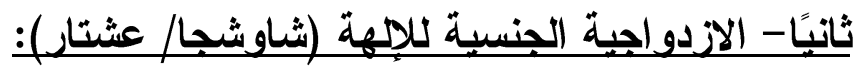

انتشرت عبادة عشتار في مناطق الشرق الأدنى القديم، وقد سماها السومريون

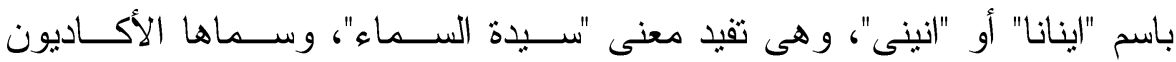

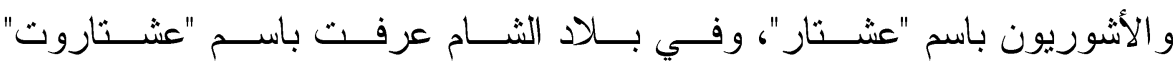

(1) Ryst, A. F., An investigation into the extensive religious and political elements that impacted on the reigns of Hattušili III, Puduhepa and their son,Tudhaliya IV (ca1267-1228 BCE), university of south Africa, 2016, p. 154f.

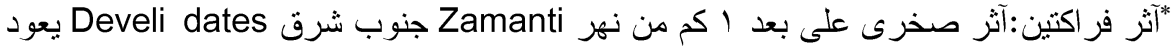

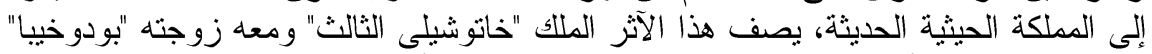

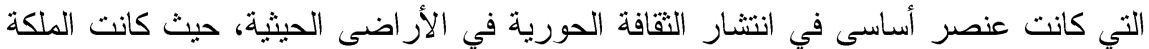

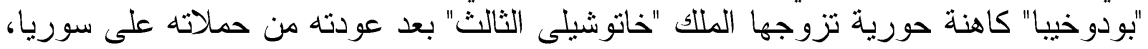

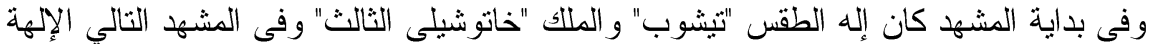

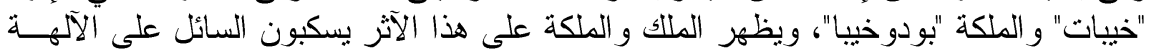

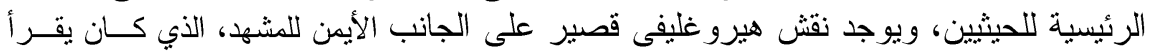

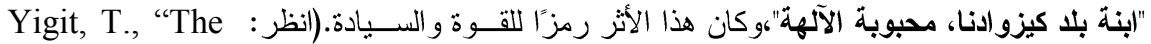
Political and Cultural Meanings of the Hittite Empire Period Rock Monuments", In: $\boldsymbol{A J H}$, Vol.2, No.1, 2016, p. 61f., Bryce, T., The routledge handbook of the peoples and places, p. 412.)

(2) Ryst, A. F., op.cit, p. 103.

${ }^{(3)}$ Ibid, p. 127f. 


\section{دورية علمية محكمة كلية الآداب- جامعة أسوان أبريل 1 ـ ب}

و "عشتوريت"، كما عبدت في المناطق العربية الجنوبية، حبــث صــار اسـمها

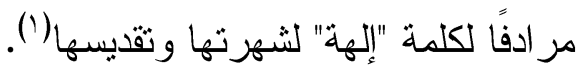

و قد وردت لأول مرة في الأناضول في النصوص التي نزجــع إلــى فتــرة المستعمرات الآشورية، و انتقلت عبادتها بحلول القرن الخامس عشر من نبنوى في شمال بـلاد النهرين عبر شمال سوريا إلى شرق الأناضول(؟) ، و غالبًا مــا يظهـر

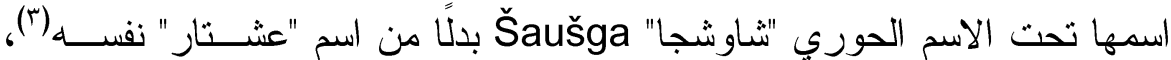

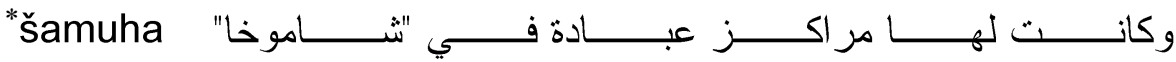

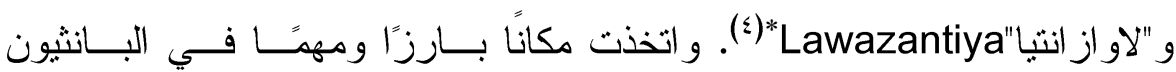
الحيثى (ن)

وقد استحوذت "شاوشجا" على العديد من سمات "اينانا" الســومرية، و "عثــتار" البابلية في جانبها الأنثوى كإلهة الحب(؟) والجنس، وهى مشهورة -بشكل خــاص (1) (أحمد أمين سليم، المرجع السابق، ص ؟0ب.

${ }^{(2)}$ Bryce, T., Life and society in the Hittite world, p.147.

${ }^{(3)}$ Allen, S., op.cit, p.87.

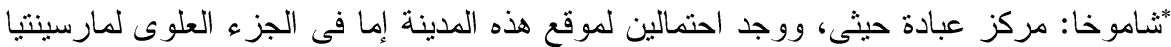
و Marassantiya

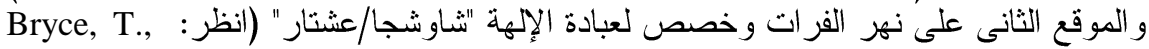
The routledge handbook of the peoples and places, p.615.)

*لاو از انتيا: مدينة فى جنوب الأناضول، فى مكان ما إلى شمال سلسلة جبال الأمانوس، وظهرت

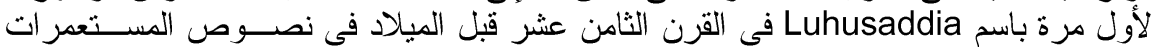

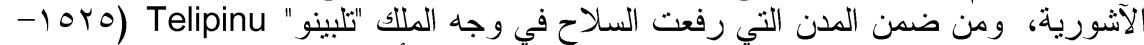

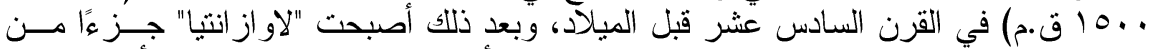

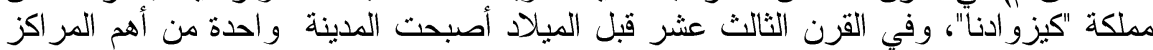

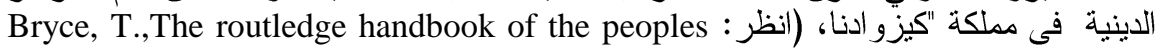
and places, p. 412.)

${ }^{(4)}$ Bryce, T.,Life and society in the Hittite world, p.145.\& Taracha, P., op.cit,p.124.

${ }^{(5)}$ Dongen, E., "The Hittite " Song of going forth" $\left(\mathrm{CTH}_{344}\right)$ : A reconsideration of the narrative". In, WdO, Bd. 42, H. 1, 2012, p.42.

${ }^{(6)}$ Taracha, P., op.cit,p.123. 


\section{دورية علمية محكمة كلية الآداب- جامعة أسوان أبريل 1 ـ ب}

كالإهة الثفاء" وعادةة ما نظهر ها المشاهد الحيثية في صورة عارية أو مغطاة جزئيًا للكثف عن طبيعتها الأنثوية(1).

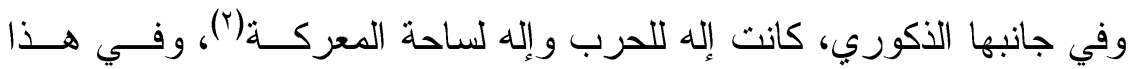
الجانب ظهرت الإلهة مع أنو اع مختلفة من الأسلحة(r)، فقد مثلت في هيئة مجنحة و اقفة على أسد أو اثثين وهي تحمل الجعبة، وفي إحدى يديها سلاح مقوس، وفـي

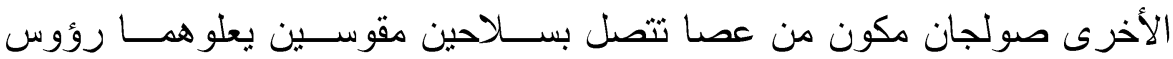
أسود())، كما صورت في كثير من الأحيان على هيئة رجل ملتحي أو أنثى ملتحية وبالأخص في نينوى(0.

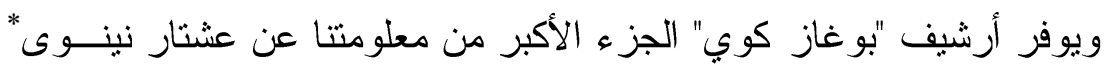
أثثاء الألفية الثانية، ولكن في العصر الحيثي القديم لم يكن لعشتار أي أهمية حقيقية

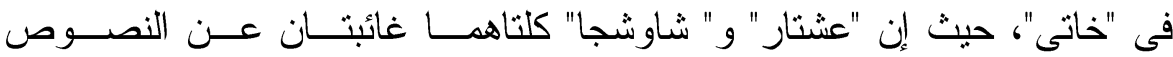
التاريخية المبكرة ، فيما عدا نص حيثي قديم يشير إلى عشتار باسم آخـر، حيــث

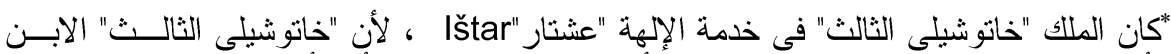

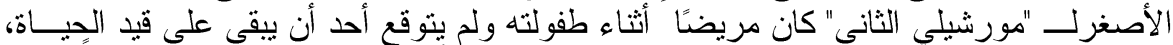

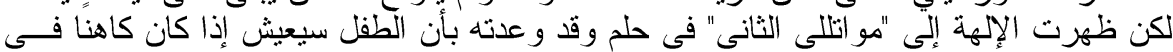

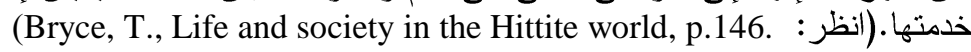

(1)Jordan, M., Dictionary of gods and goddesses, New York, 2014, p.278., Alexander, R., op.cit,p.167.,Bryce, T.,Life and society in the Hittite world, p.147.

${ }^{(2)}$ Bryce, T.,Life and society in the Hittite world, p.147.

${ }^{(3)}$ Taracha, P., op.cit,p.123.

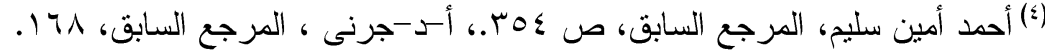

$$
\begin{aligned}
& \text { (0)اصر محمد مكاوى- عزيز محمد عزيز : عشتار ومدينة أربيل، مجلة در اسات فــي التـاريخ }
\end{aligned}
$$

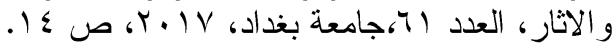

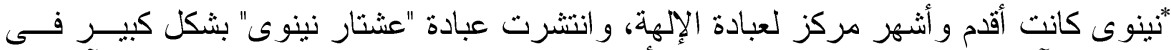

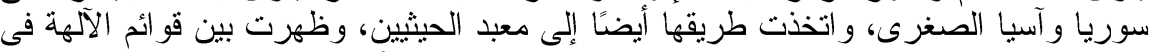

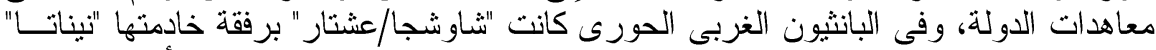
Ninatta نينوى.(انظر : Taracha, P., op.cit, p.124) 
وجد عدد من الآلهة الخاتية تسميات مختلفة بين البشر وزملائهم الآلهــه، حيــث

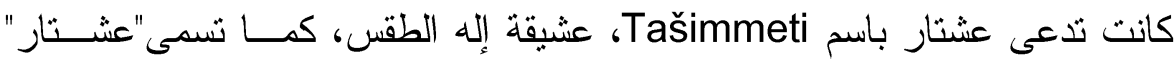

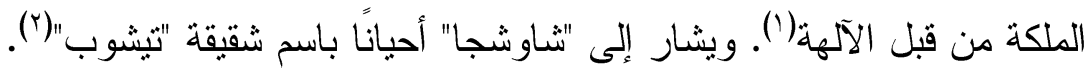
و اكتسبت عشتار أهمية كبيرة في "خاتى" خلال العصر الحيثـي الوسـبط ، كإلـــه

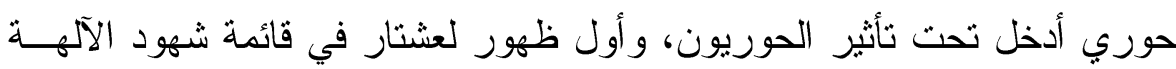

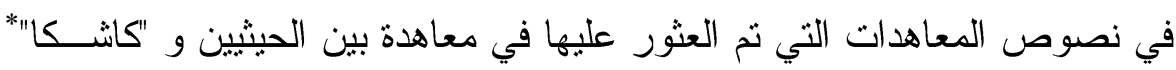

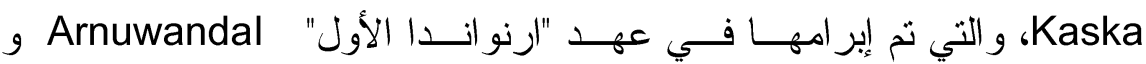
"الثمونيكال" Ašmunikkal"

وقد ساعدت طبيعة الازدو اجية الجنسية الإلهة "شاوشجا/عشتار" علــى ممارســة

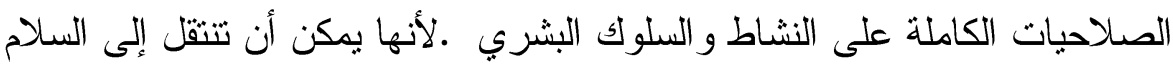

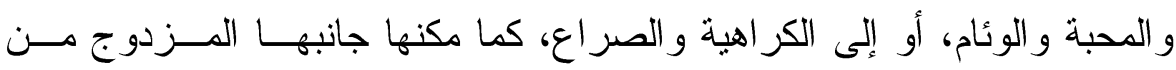

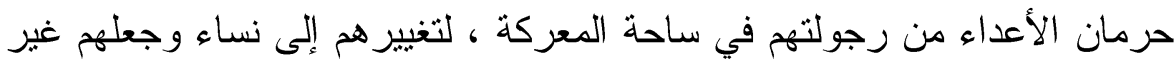
قادرين على القتال (乏).

ويتضح ذلك فى النصوص الحيثية للإلهة "شاوشجا/عشتار"، و المتمثل فى الطقوس

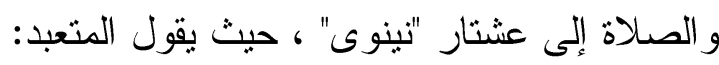

${ }^{(1)}$ Beckman,G.,"Ištar of Nineveh reconsidered". In, JCS, vol. 50, 1998, p.3.

${ }^{(2)}$ Stricklin, D., Hittite culture and mythology I, 2015, p.52.

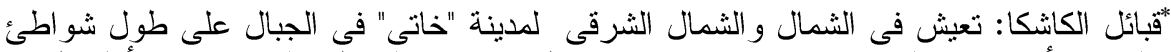

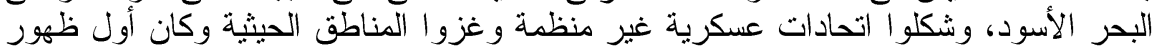

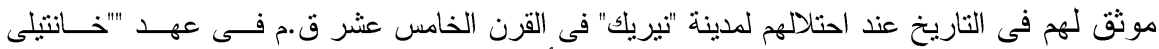

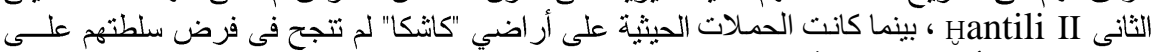

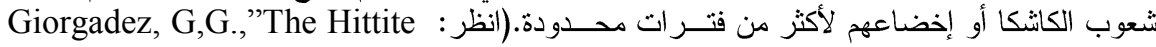
kingdom", In.Early Antiquity, Edit by Diakonoff, I. Chicago and London, 1991, p.275, Bryce, T., The routledge handbook of the peoples and places, p. 412.)

${ }^{(3)}$ Beckman,G.,"Ištar of Nineveh reconsidered", p.3.

${ }^{(4)}$ Bryce, T., Life and society in the Hittite world, p.147.. 


\section{دورية علمية محكمة كلية الآداب- جامعة أسوان أبريل 1 ـ ب}

"خذ من الرجال (الذكورة)، البراعة، الصحة القوية، السيوف، فؤوس المعركــة،

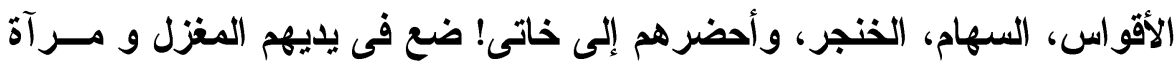

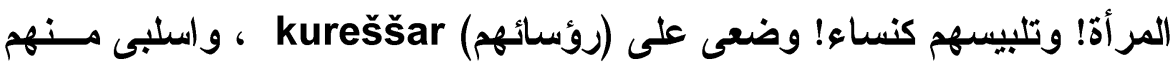
لصالحك (').

وبما أن الإلهة "شاوشجا/ عشتار" تتسم بصفات الإلهة السومرية "اينانا" مع الإلهـــة السامية "عشتار" وكلتيهما تذهبا إلى المناطق السفلى وتعودا إلــى عـــالم الــدنيا،

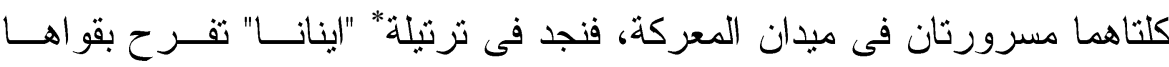

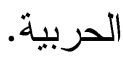

"عندما أقف فى خط المعركة (الأمامى)، أنا قائد جميع الأراضى، عندما أقف فـى

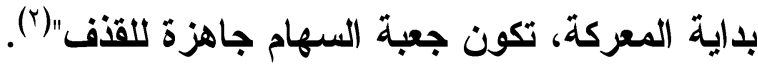

وتكثف الحفائر إلى جانب النصوص الحيثية عن الطبيعة الجنسية المزدوجــة للإلهة "شاوشجا/عشتار"، حيث أظهرت الحفريات أنها ترتدي تاجًا. وكانت تصور

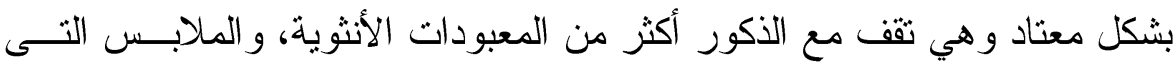
ترتديها تشبه ملابس المحاربين فى الجيش الحيثى ().

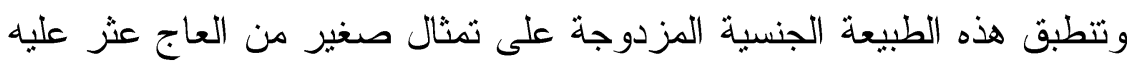

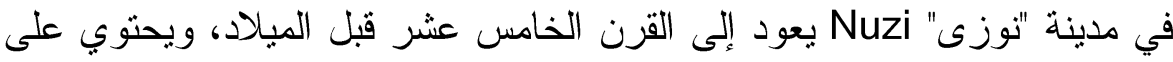
عناصر من ملابس الرجال و النساء، حيث إن الجذع العلوي للتمثال مغطى بثيابه،

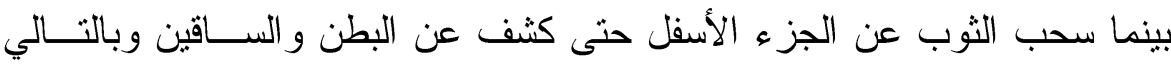

${ }^{(1)}$ Hoffner, H., "Symbols for masculinity and feminity: Their use in ancient near eastern sympathetic magic rituals", JBL, Vol. 85, No. 3, 1966, p.331.

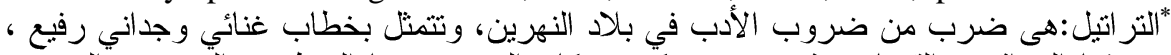

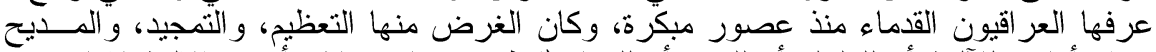

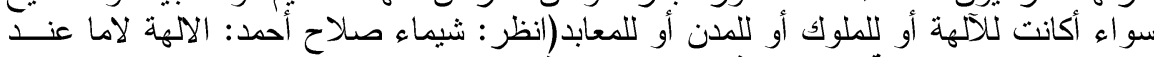

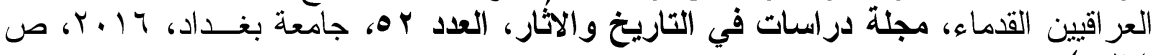

${ }^{(2)}$ Motz, L., The faces of the goddess, Oxford, 1997, p.35.

${ }^{(3)}$ Stricklin, D,op.cit, p.52. 
تظهر طبيعة الأنثى للتمثال، إلا إنه يحتوى علـى عناصــر للمابــس الذكوريـــة و الأنثوية، وفأس معركة في يد واحدة وعلى المثلث الآخر نقش هيروغليفي حيثي

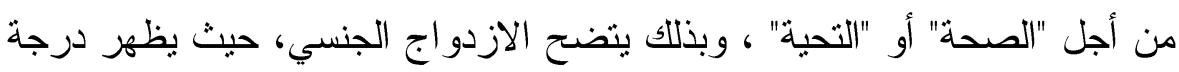

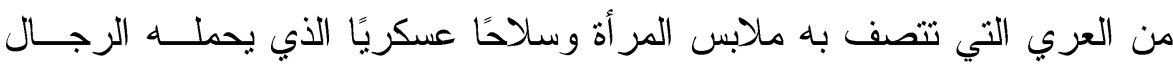

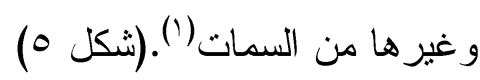

وتظهر الإلهة "شاوشجا/عشتار" فى صورة الأنثى وهى عاريــة علــى أثــر

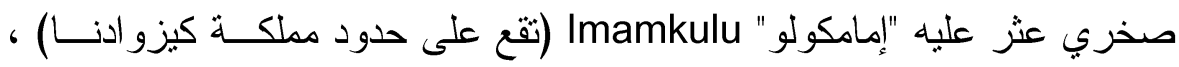
يعود إلى أواخر القرن الثالث عشر قبل الميلاد، نظهر الإلهة وهي عارية وتحمل

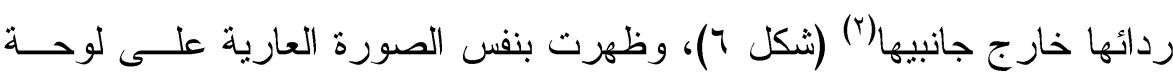

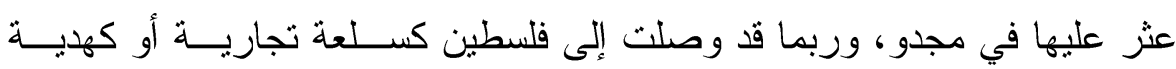

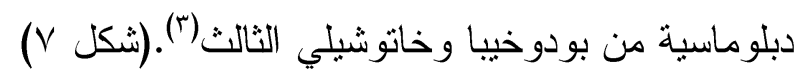

وظهرت الإلهة على جدران المزار الملكي في "يازيليكايــا" بطبيعــة جنســـا

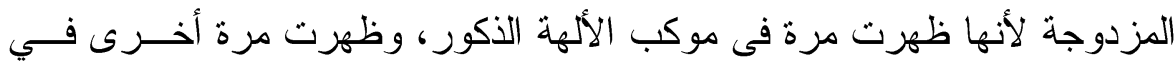

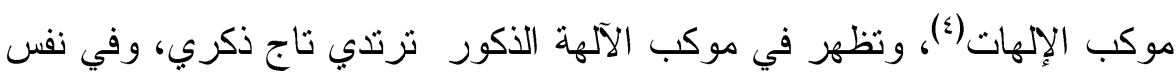

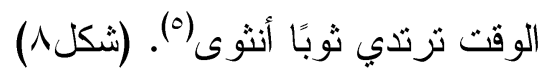

وتظهر الإلهة بالملابس المطوية (المثنية) و التي تتنمي إلى النساء الحيثيــات،

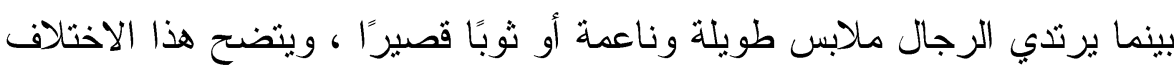

(1) Alexander, R, op.cit,p.171.

${ }^{(2)}$ Ibid, p.169.

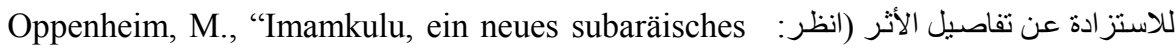
Denkmal aus der Hettiterzeit in Kleinasien”, In. AFO, 11. 1936-1937, pp.341-350)

${ }^{(3)}$ Ryst, A. F., op.cit, p. 91.

(4) Jones, L.,op.cit, p.3595., Hoffner, H., "Symbols for masculinity and feminity, p.334.

${ }^{(5)}$ Alexander, R., op.cit,p.172. 


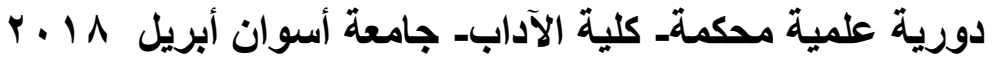

بين الألهة و الإلهات في موكب "يازيليكايا"، و عادةً تكون ثتايا ملابس الإلهات تسقط

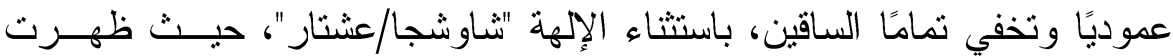

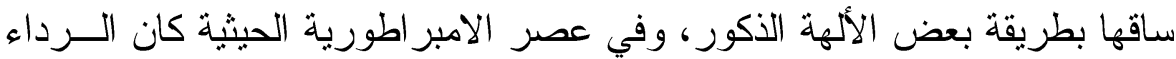

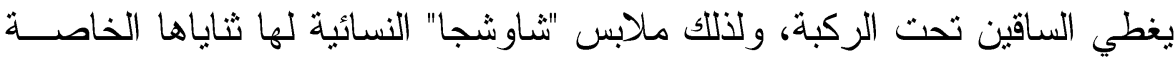

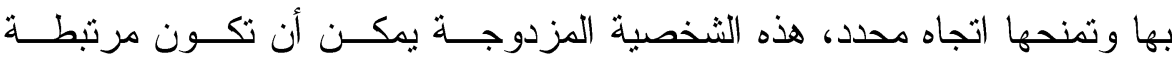
بنصوص معينة نوضح طبيعتها المزدوجة فى آن واحد (مذكر ومؤنسـث) و التــي هردي

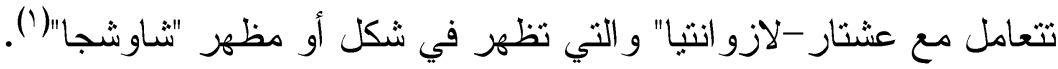
"تزتدى ثيابك الرجالية، وتظهزى بنمط امرأة "(؟).

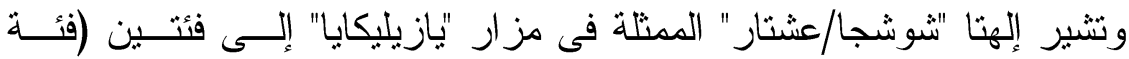
الحرب وفئة الحب)، واحدة تظهر بين الألهة الذكور وتوحي بالصفات الحربيــة، و الأخرى تظهز مع الإلهات لنتخذ صفة الحب لهذه الفئة (ب).

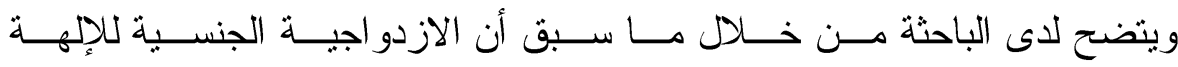

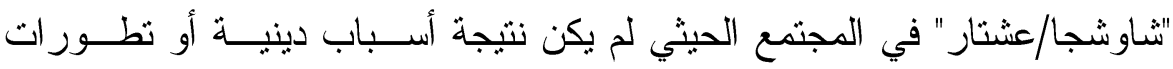

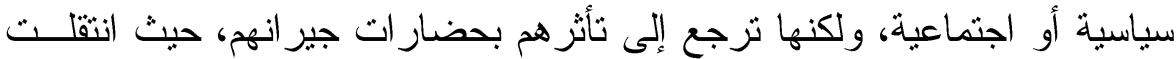

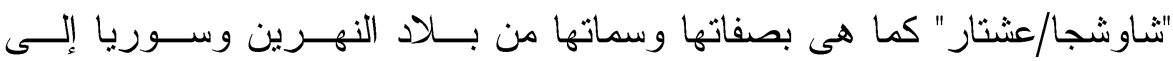

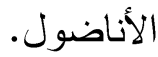

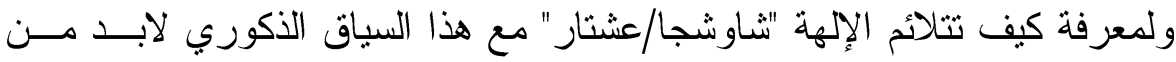

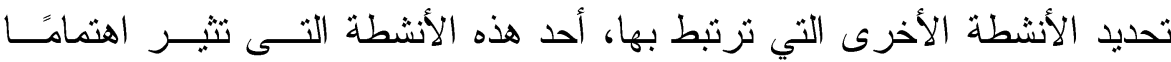

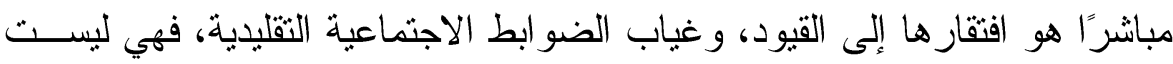

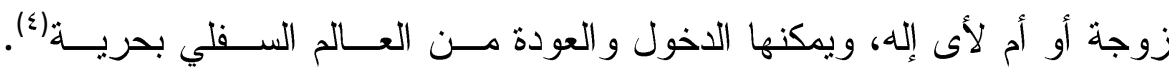
بالإضافة إلى ارتباط الإلهة "شاوشجا/عشتار" بالعلاقات الجنسية، والتي تجسدها أول وله

${ }^{(1)}$ Danmanvilie, J., “ Iconographie d'Ištar-šaušga en Anatolie ancienne, In. $\boldsymbol{R A}$, vol.56, No.1, 1962, p.22f

${ }^{(2)}$ Ibid, p.23.

${ }^{(3)}$ Allen, S., op.cit, p. 87.

${ }^{(4)}$ Kuhrt, A.,"Women and War", In.NIN, Vol.2. 2001, p.21. 
تدمجها الإلهة في شخصيتها، وكانت هذه العلاقات ينظر إليها علــى أنهـــا مفيـــة

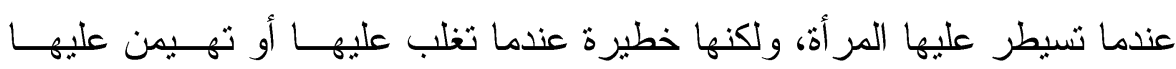
الشريكة الأنثى أو الزوجة، لذلك القوة التي تجسدها الإلهة متتاقضة إلى حد مــا،

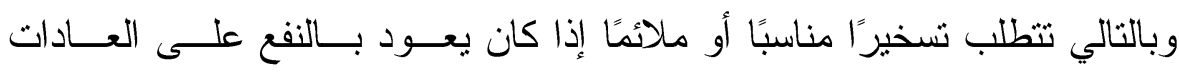

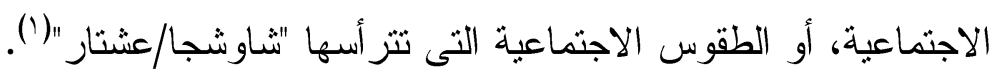

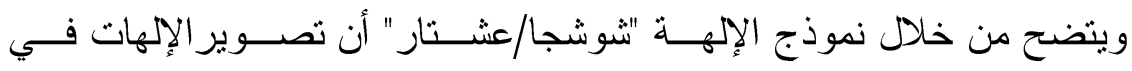

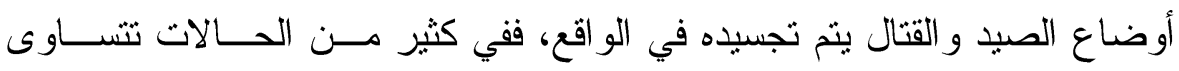

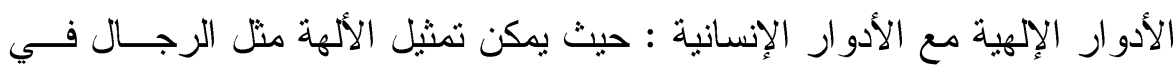

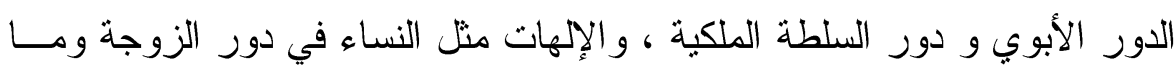

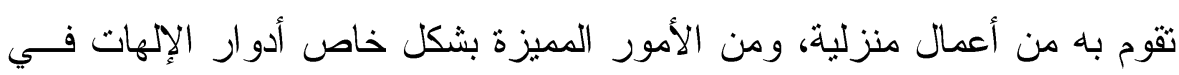

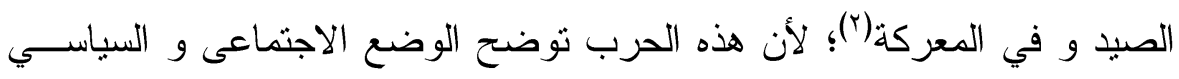

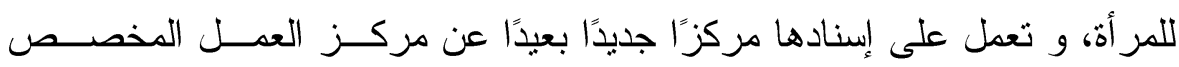

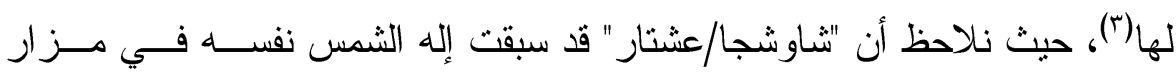

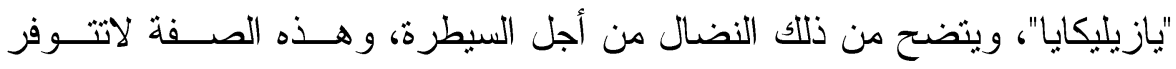

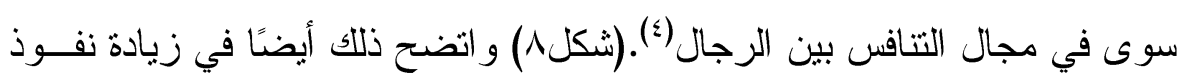
وسلطة الملكة بودوخيبا و الذي انعكس ذلك بدوره على البانثيون الحيثـي، حيــث

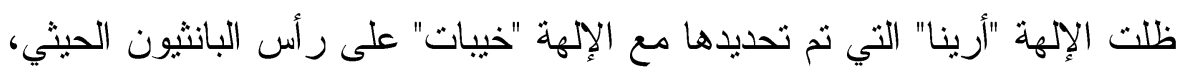

${ }^{(1)}$ Kuhrt, A. op.cit, p.21.

${ }^{(2)}$ David, S., "Transformation of a goddess: Ishtar- Astarte - Aphrodite". In, $\boldsymbol{O B O}$, Vol. 263, 2014, p.57.

${ }^{(3)}$ Kuhrt, op.cit, p.19.

${ }^{(4)}$ Laroche, E., "Panthéon national et panthéons locaux chez les Hourrites", In. Or NS, Vol.45,1976, p.98. 


\section{دورية علمية محكمة كلية الآداب- جامعة أسوان أبريل 1 ـ ب}

بينما ثر اجع مكانة إله الشمس المتمثل في صورة الملك('). وهذا يوضـح التتــافس بين الملك و الملكة(ب). وبذلك لم يجد الحيثيون صعوبة في فكرة قيام الآلهة بأدو ار الذكور و الإتـاث، و هو ما أوضحته الباحثة في الصفحات السابقة. ومن الأفضل تتاولها وتصـــويرها على أنها ذكر أو أنثى من خلال الدور الذى تقوم به، وهذا و اضتح فـــي المفــاهيم

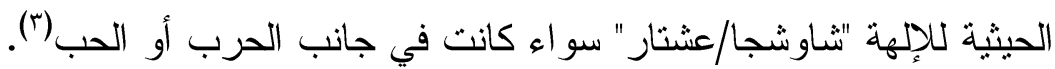

\section{ثالثًا- تغبر نوع جنس الإله عند الاتثقال من حضارة لأخرى.}

كانت بعض الآلهة يتغير / يتحول نوع جنسها عند انتقالها من حضارة إلى حضارة

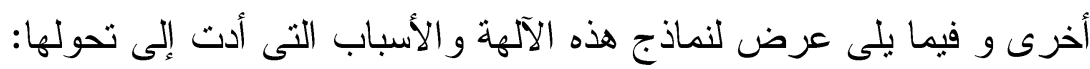
| -أصبحت الإلهة الخاتية "كايت" kait (إلهة الانبات)، هى الإله الحيثي "خـالكى خالكيش" Halki / Halkišs (إله الحبوب)(؟).

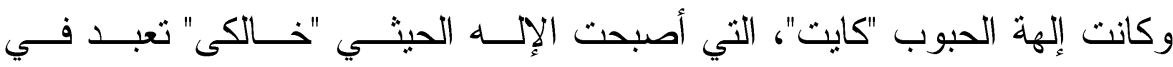

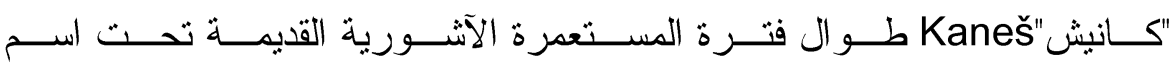
"نيسابا"* Nisaba وذا يمكن أن يشهد على التأثير المبكر لمعتقدات بلاد النهـرين على الدين الحيثي (').

${ }^{(1)}$ Winter, W, op.cit, p.449.

${ }^{(\uparrow)}$ Marinatos, N., op.cit, p.35.

${ }^{(3)}$ Bryce, T., Life and society in the Hittite world, p.143.

${ }^{(4)}$ Jones, L., op.cit, p.3595.

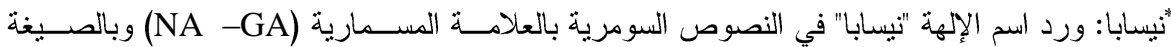

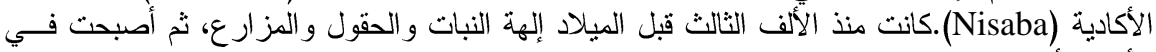

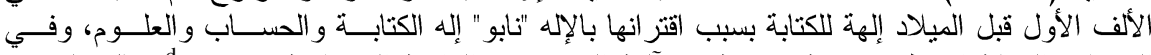

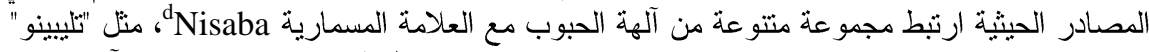
Telepinu

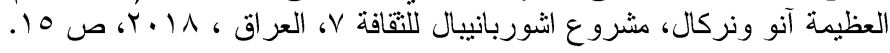


r- الإله أو حاكم العالم السفلي الخاتي/الحيثي "ليلوانى" "Lelwani تغير إلى إلهـــة

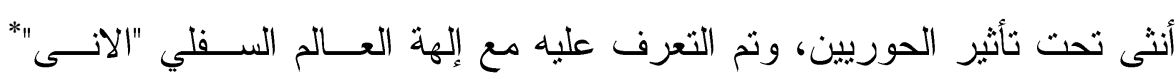
(r)Allani

ب- الإله "لاما" المعروف كإله الحراسة فــي النصــوص الســومرية بالعلامـــة

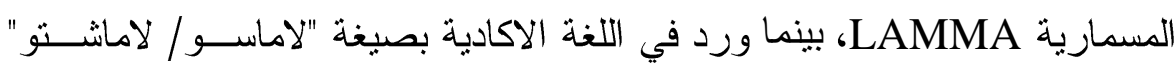
Lamasu/Lamaštu

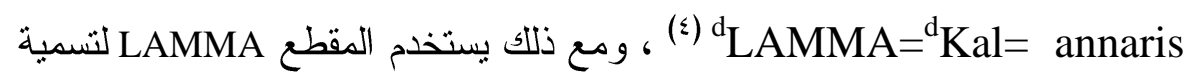
ألهة ذكورية مختلفة، ويوجد عدد كبير من LAMMA فى المــدن (०. وبمــا أن

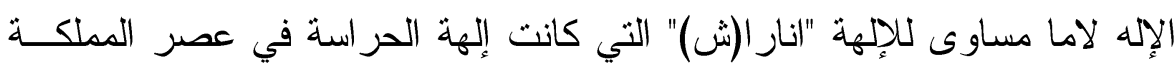

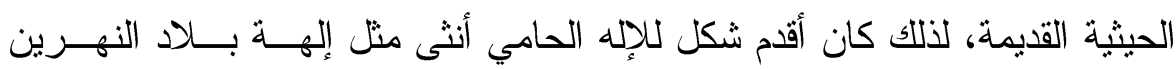

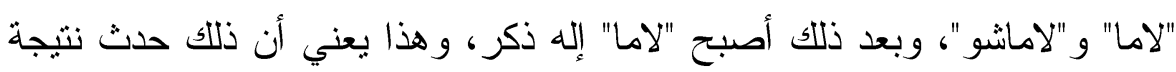

Leick, G., A dictionary of ancient near eastern mythology, London\&New York, 1991, p.138.)

${ }^{(1)}$ Taracha, P., op.cit, p.29.

تتم تحديد دور إلهة-الثمس بشكل شائع مع الإلهة الخاتية "ليلو انى" (ملكة الآلهــة فـي العـالم السفلى).(انظر : . (Lerner, G., op.cit, p.158)

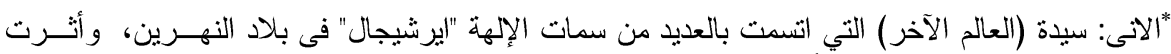

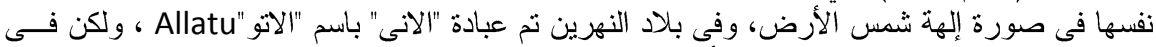

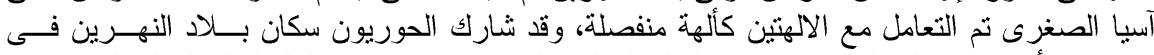

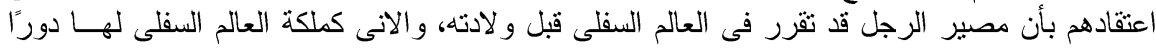
فى ذلك.(انظر : . Taracha, P.,op.cit, p.124)

${ }^{(2)}$ Stricklin, D,op.cit, p.54., Jones, L.,op.cit, p.3595.

$$
\text { (r) شيماء صلاح أحمد، المرجع السابق، صــــ. }
$$

-Karasu, C., op.cit, p.230.

${ }^{(4)}$ Leick, G., op.cit, p.110.

${ }^{(5)}$ Karasu, C., op.cit, p. 230 


\section{دورية علمية محكمة كلية الآداب- جامعة أسوان أبريل 1 ـ ب}

تطور في تاريخ الحضارة الحيثية، وليس اختلافًا أساسيًا في تصور ات أو معنقدات

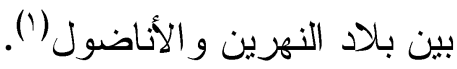

؛ - إلهة الحر اسة الحيثية "الا" ALA تم عبادتها كإله ذكر في بلاد النهرين تحت

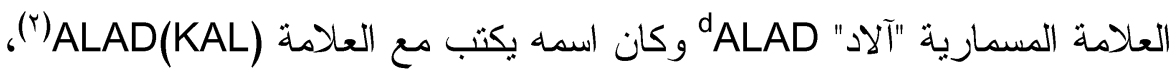

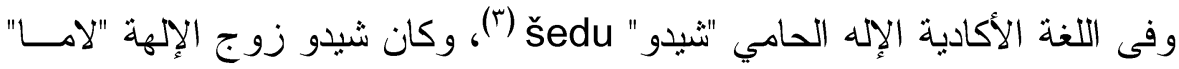

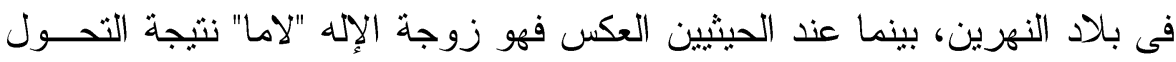

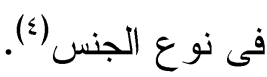

ويتضح مما سبق أن كثرة الآلهة عند الحيثين برجع إلى مقاومتهم التوفيق بين

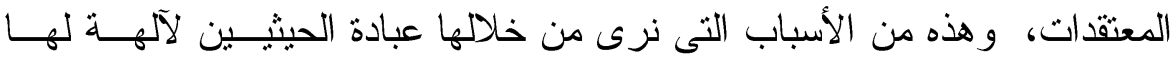

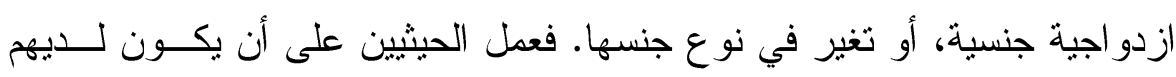

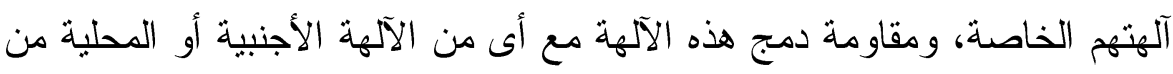

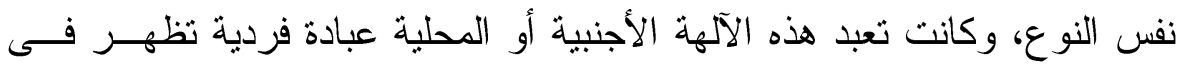

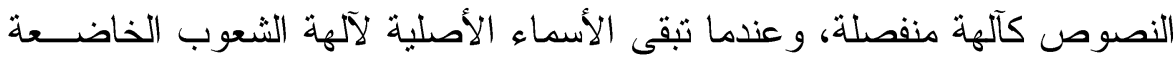

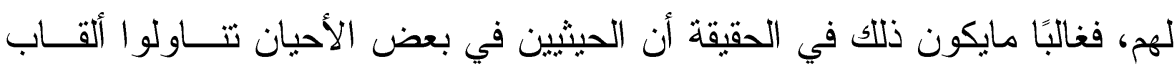

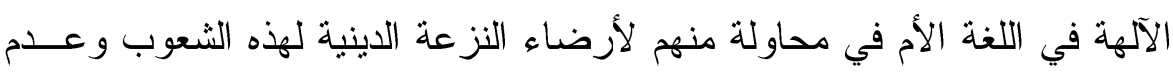
فرض الحيثين إلهنهم عليهم (0). على سبيل المثال إله السماء الثمس "ايشتانو" عبد

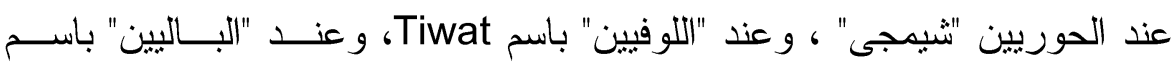
Tiwaz

${ }^{(1)}$ McMahon, G., The Hittite state cult of the tutelary deities, Assyriological Studies, No.25, Chicago.1991, p.25.

${ }^{(2)}$ McMahon, G.,op.cit, p.11.

( $\left.{ }^{\top}\right)$ Haas, V., op.cit, S. 449. (4) شيماء صلاح أحمد، المرجع السابق، ص .00.

-McMahon, G.,op.cit, p.11.

${ }^{(5)}$ Collins, B., op.cit, p.173.

(6) Ibid, p.173. 
رابعًا- تناقض أدوار بعض الآلهة مع طبعتهم الجنسبة من خلال الأدب.

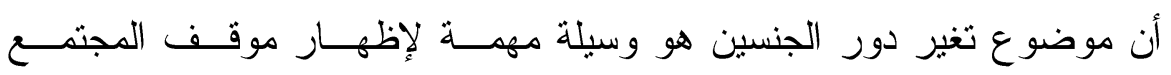

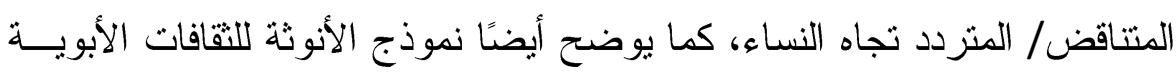

$$
\text { في الشرق الأدنى القديم ('). }
$$

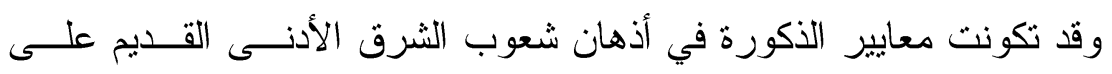

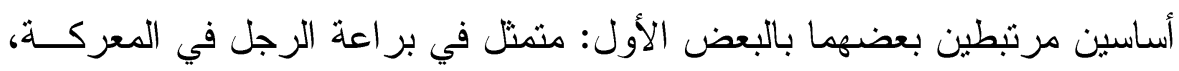

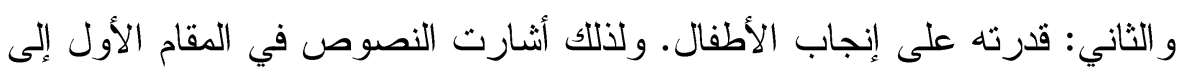

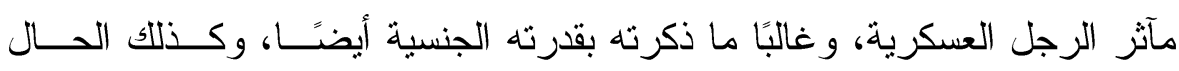

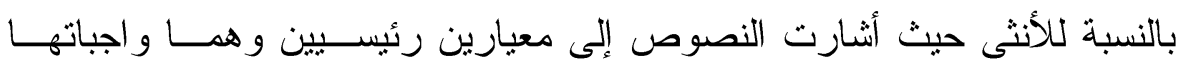

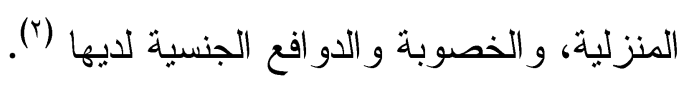
وسنوضح من خلا أسطورة حيثية قديمة تغير لدور الجنسين، وليس تغير في

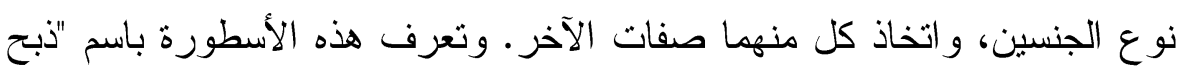

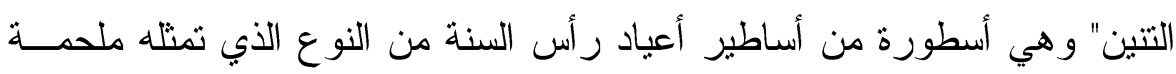

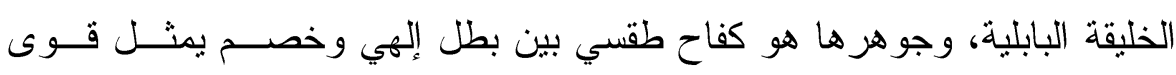

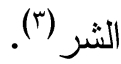

وتبدأ الرواية بهزيمة إله الطقس من التتين "الويانكا/"lluyanka، ولذلك استنجد

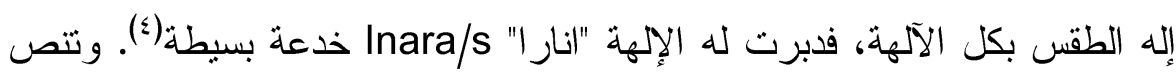

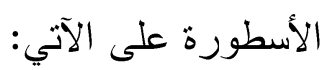

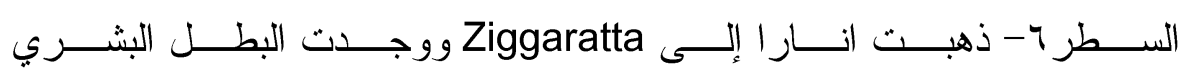
"خوباشييا" Hupašiya.

${ }^{(1)}$ Brison, O., " Aggressive goddesse, abusive men: gender role change in Near Eastern mythology", In.SMEA, vol.49, 2007., p.67.

${ }^{(2)}$ Hoffner, H., " Symbols for masculinity and feminity,p.327

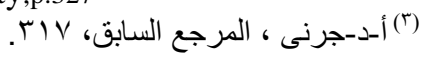

$$
\begin{aligned}
& \text { (5) المرجع السابق، VIr VI. }
\end{aligned}
$$




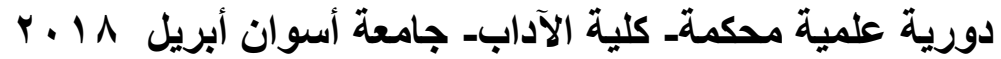

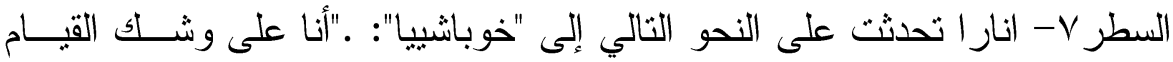

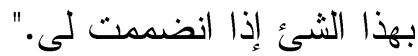

السطر ^- "خوباشييا" أجاب على النحو الثالي: "إذا كان من الممكن أن أنام معك، فسآتي و أفعل ماتريدين". و على ذلك نامت معابه.

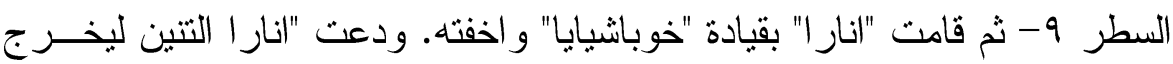
من جحره، (قائلة:) أنا أعددث وليمة. تعال تتاول الثر اب.

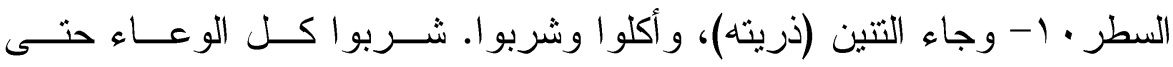

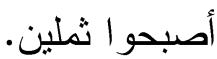

السطر 11 - الأن لا يريدون العودة إلى الحفرة مرة أخرى. جاء "خوباشيايا" وقــام بتقييد التنين بالحبل. السطر ب ا - جاء إله الطقس وقتل التتين، و الآلهة كانت معه.

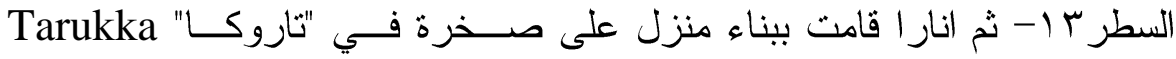

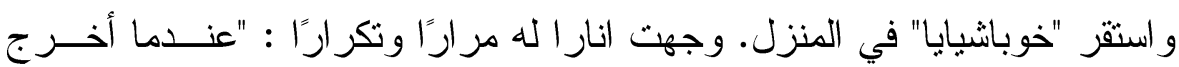
إلى البلد المفتوحة، لا تتظر خارج الثباك. لو أنت نظرت إلى الخارج سوف ترى زوجنك و أطفالك.

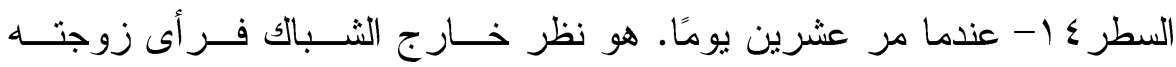
و أطفاله (').

ومن النص السابق يتضح إن تغير دور الجنسين في هذه الأسطورة منمثل في

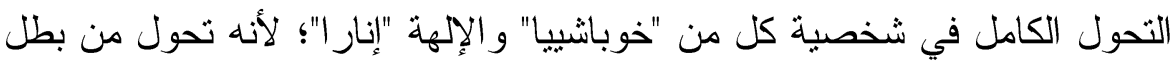
ذكر إلى شخصية "أنثوية" في تصرفاته، هذا التحول ظهر في عدة عناصر وصفتها

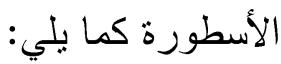

1- بنت انار ا منزلًا واستقر فيه "خوباشييا"(r) ، في هذا العنصر نجد أن الإلهة

${ }^{(1)}$ Hoffner, H., Hittite Myths, Atlanta, 1990, p.12., Beckman, G.,"The Anatolian myth of Illuyanka*",JANES, vol.14, 1982, p.18f., Pritchard, J. B., Ancient Near Eastern texts, Relating to the Old Testament, Princeton. New Jersey,1969, p.125f., Blasweiler, J., The cult of the Kursa in the kingdom of Hattusa,the Illuyankamyth and the way to colchis, Netherlands, 2014, p.16.

${ }^{(2)}$ Brison, O.,op.cit, p.72. 
انارا اتخذت الدور القيادي الذي يمثله الرجل؛ لأنه من المفترض أن الرجـلـ

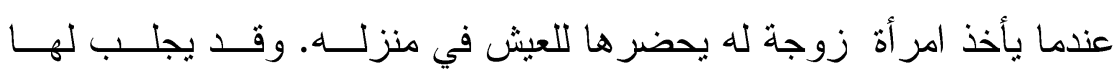

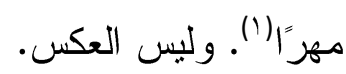

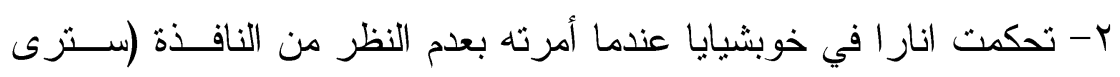
زوجناك و أطفالك")

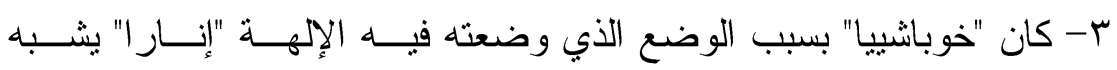

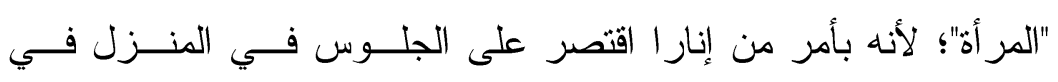

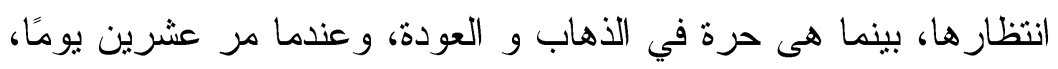

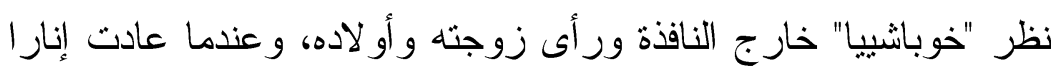

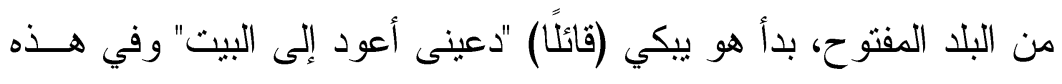

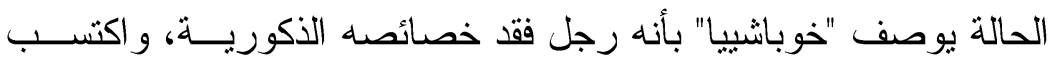

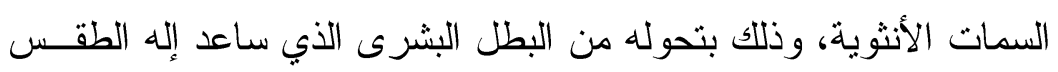

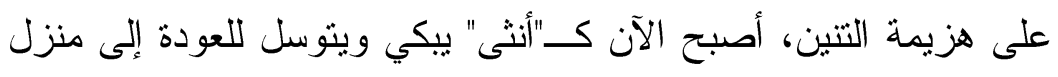

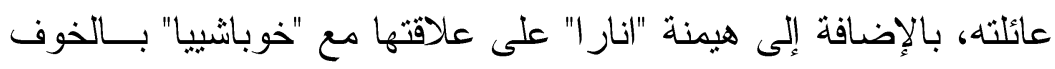

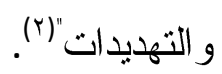

ويمكن أن نوضح أن السبب في تغير الدور الذى قامت به الإلهـــة "انــار ا"

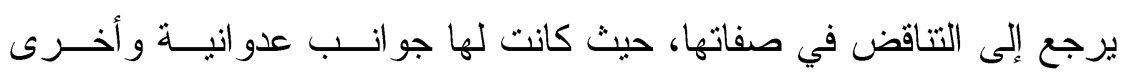

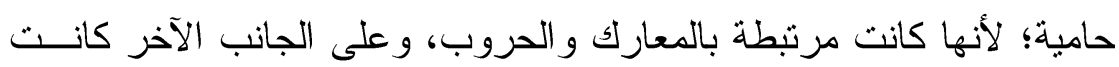
إلهة حامية للأرض و حامية للحيو انات(").

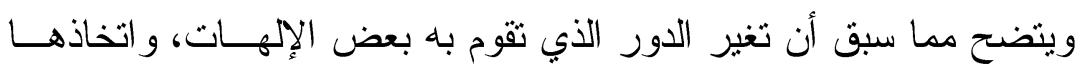

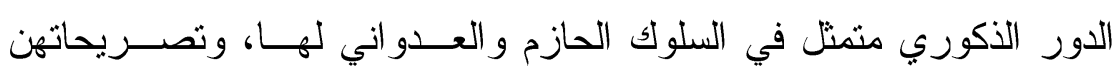

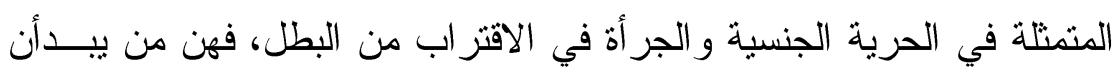

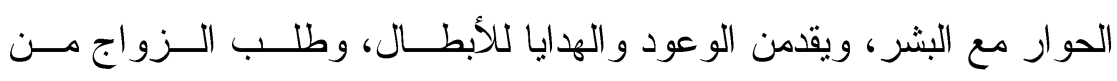

${ }^{(1)}$ Hoffner, H, A., The laws of the Hittite, PhD. Barndies university, 1963, p.178.

(2) Brison, O.,op.cit, p. 72.

(๗) Haas, V., op.cit, S. 437. 
الرجال، و إقامتهن للمنزل ، و وغير ها من الأمور التي تمنع بها الرجال في هذه

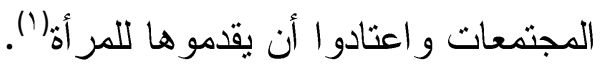

\section{نتائج البحث:}

يمكن استخلاص نتائج البحث على النحو الآتي:

1- لم يفرض الحيثيون معتقداتهم على الشعوب الأصلية في المناطق التي غزوها وسيطروا عليها، بل تبنو ا بعض عناصر ثقافات هذه الشعوب

$$
\text { و التي وجدوا أنها مناسبة لهم. }
$$

r- حاول الحيثيون احتواء ودمج الشعوب الأخرى تحت سيطرتهم وذلك بتبنى

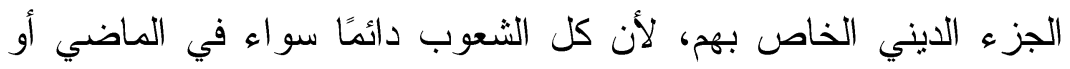

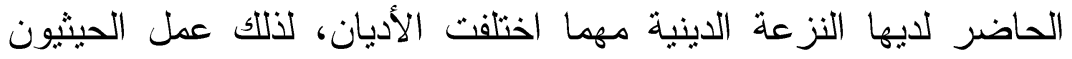

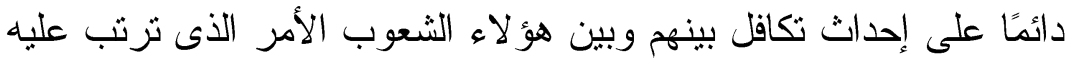
في أغلب الأحيان إحداث تغيير في نوع جنس ونس الآلهة. ب- ترجع أسباب الازدواج الجنسي للآلهة في الأغلب إلى أسبان أسباب اجتماعية

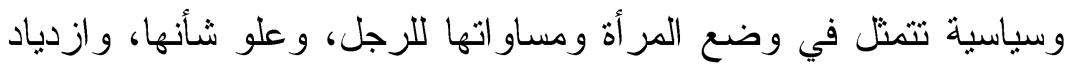

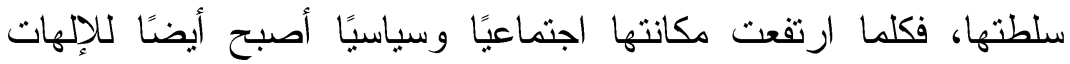

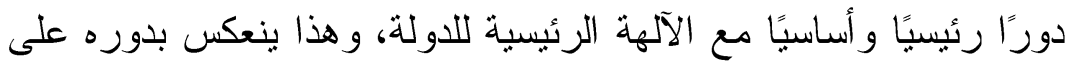
تطور السلطة السياسية في الو اقع. ع- محاولة المر أة في مجتمعات الشرق الأدنى القديم باحتلال مكانة بارزة في

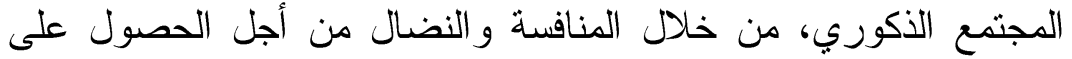

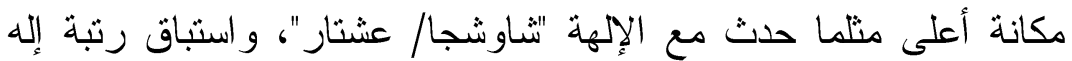
الثمس في مز ار "يازيليكايا".

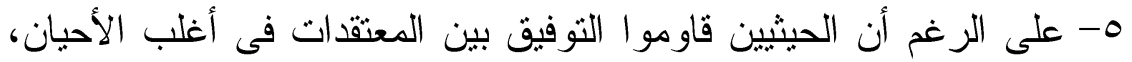

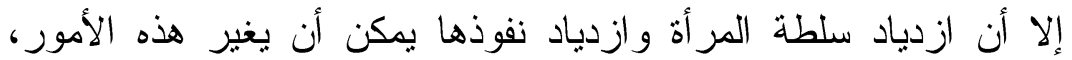

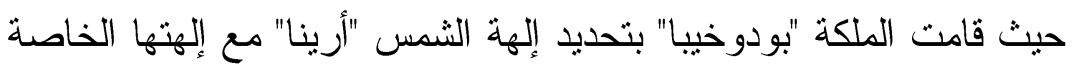
"خيبات"، و هذا يعود إلى قوة نفوذها وسلطتها في الإمبر اطورية.

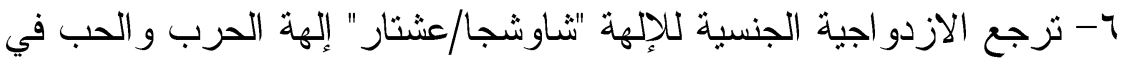
الأغلب من خلال تحليل شخصيتها إلى افتقادها للتقاليد المجتمعية المنمثلة

${ }^{(1)}$ Brison, O.,op.cit, p.70. 
في القيود و الضوابط المفروضة على المرأة، وحريتها فى الذهاب

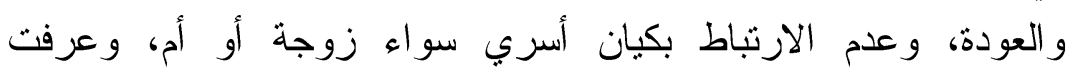

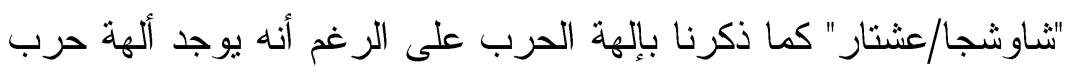

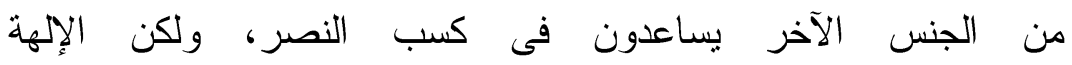

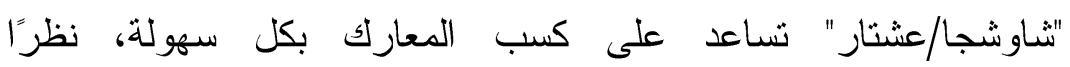
لاستخدامها أسلحة غير تقليدية و المتمثلة في الجنس. إذ تتحول في مئمل ميدان المعركة من الطبيعة الذكورية إلى امر أة تضعف فلعة العدو، ويجعله يخسر

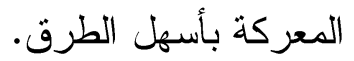

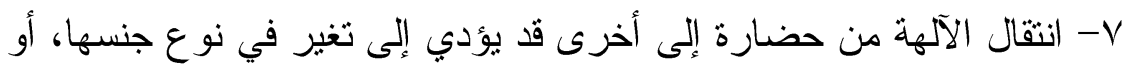

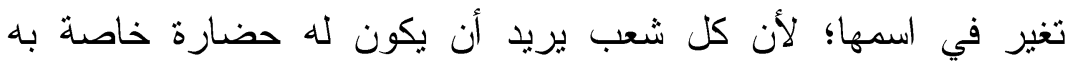
ومنفردة عن غيره.

1- لم تقتصر الازدواجية الجنسية على جنس الآلهة ولكنها امتذت إلى التغير

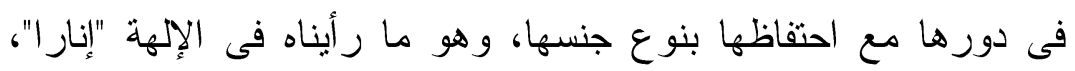

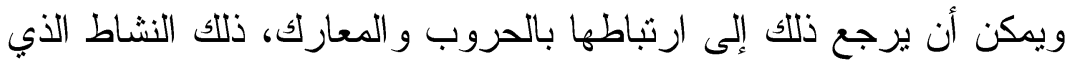

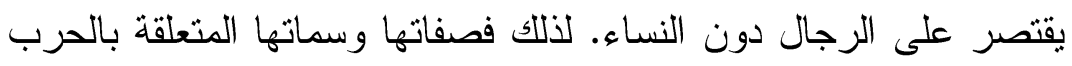

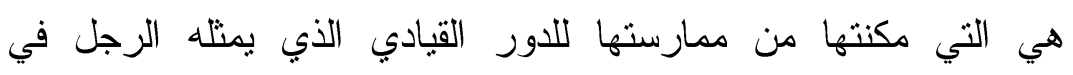
مجتمعات الشرق الأدنى القديم. مكن مان 

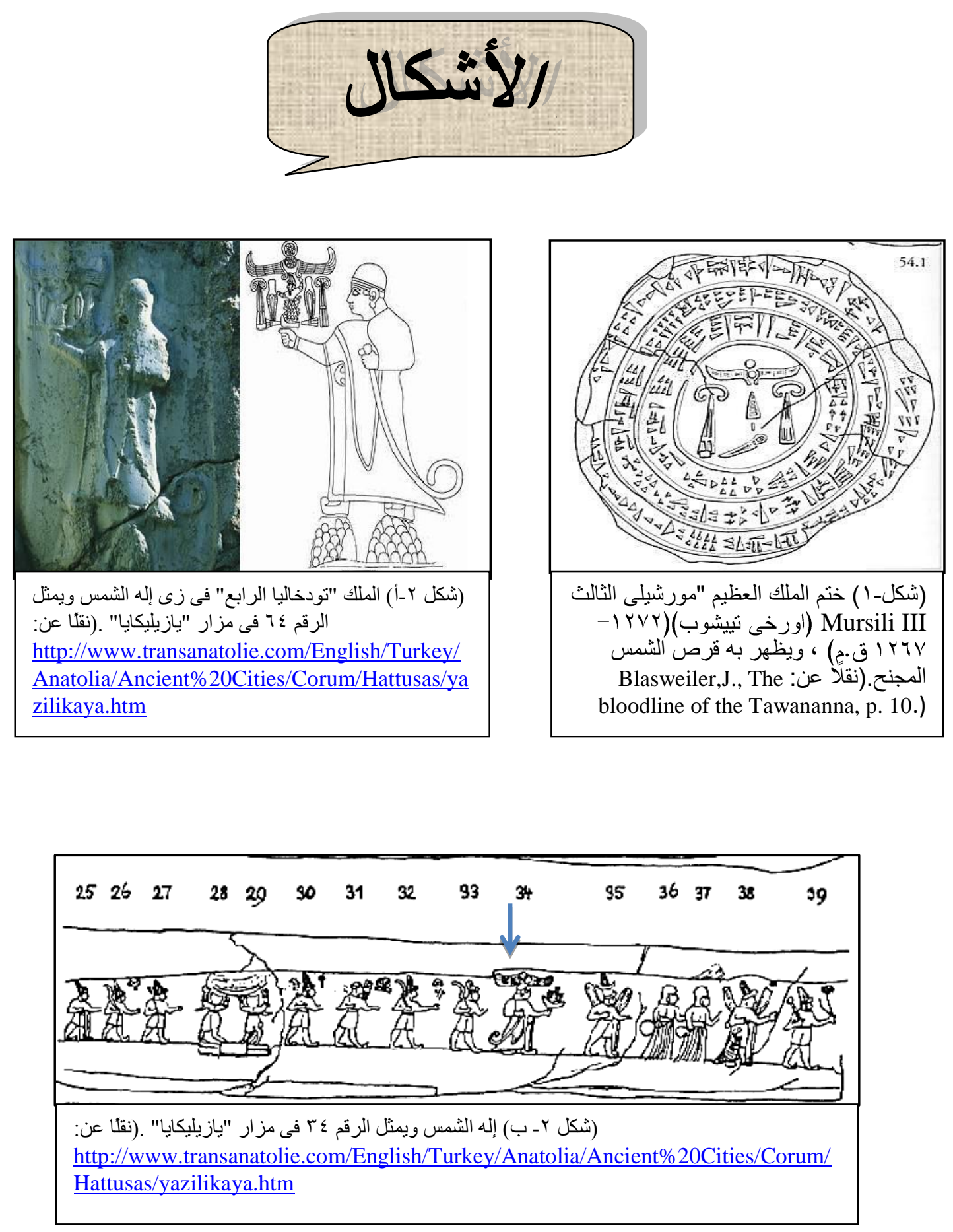

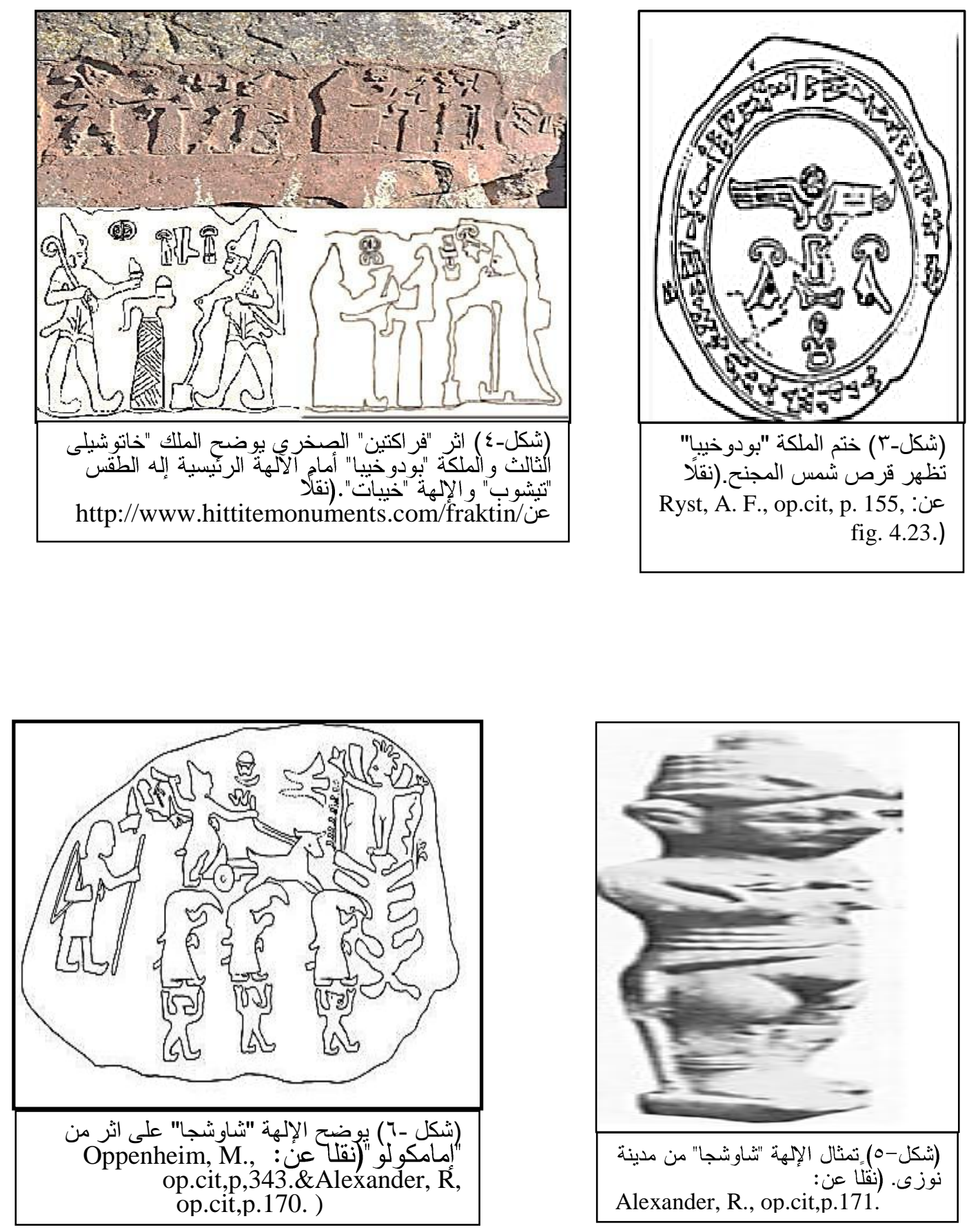


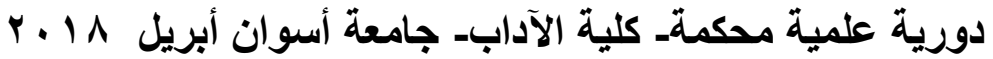

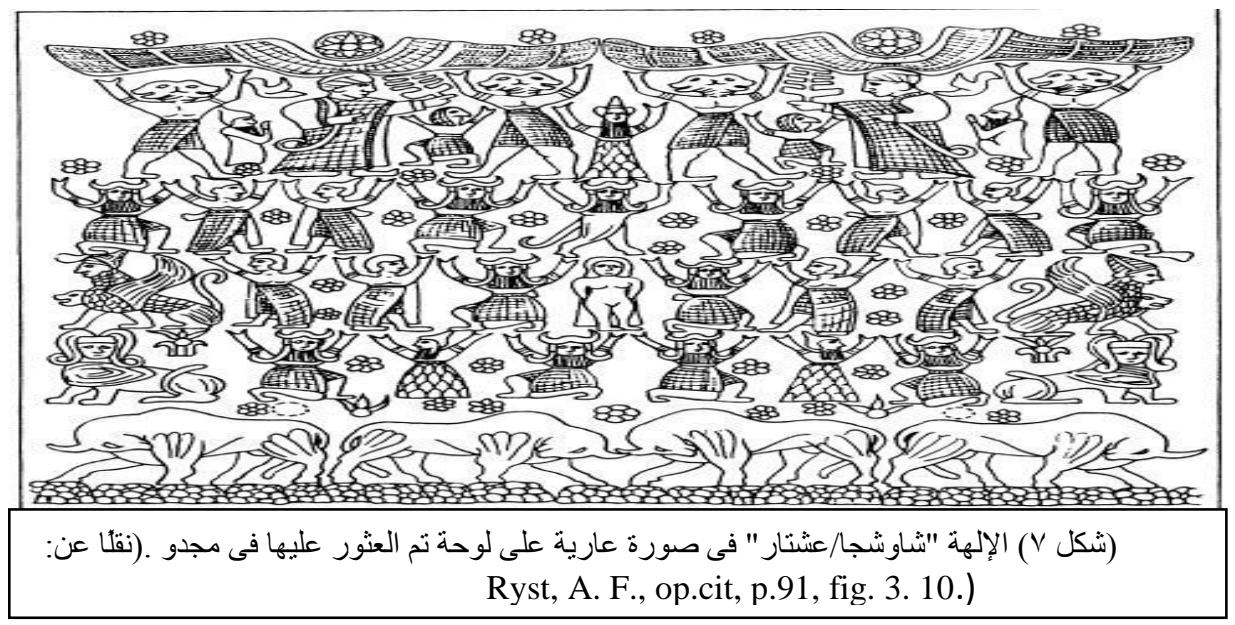

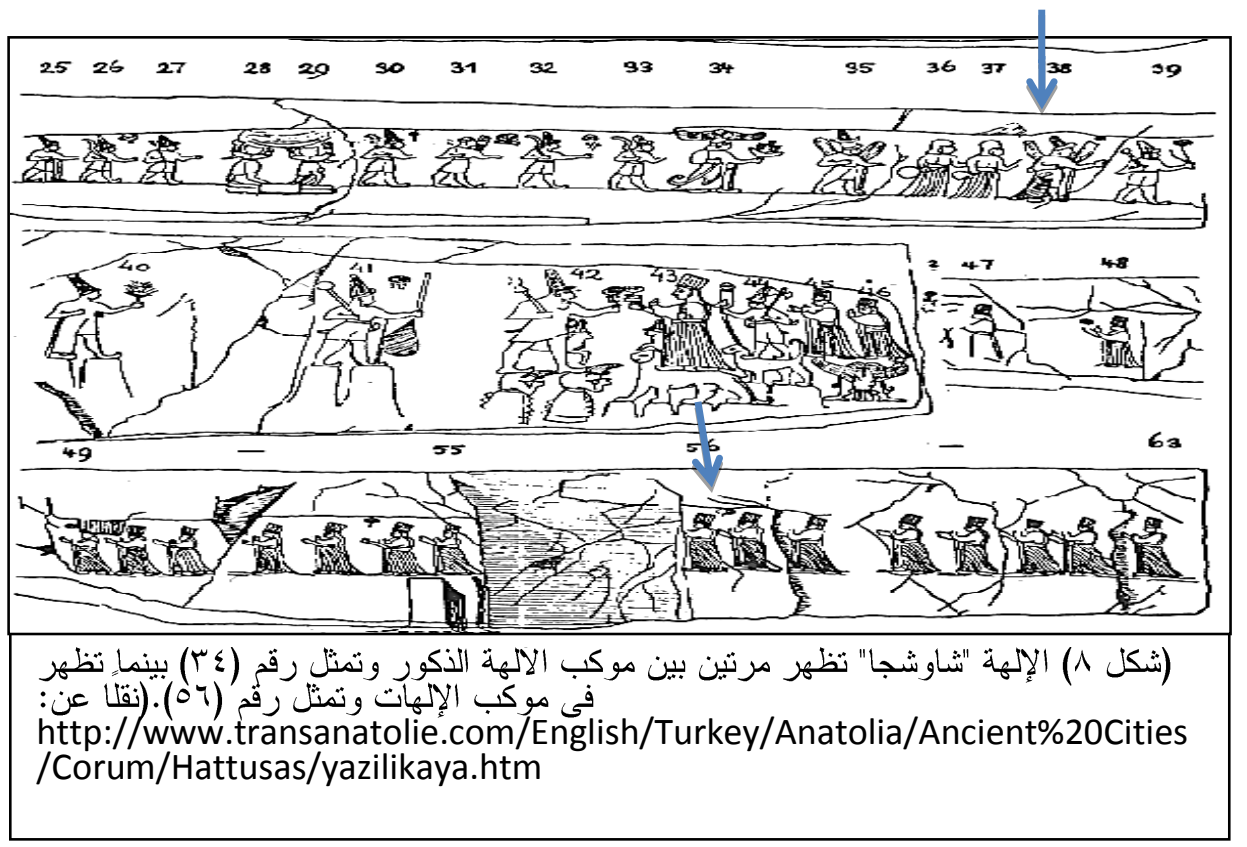




\section{قائمة المصادر والمراجِع}

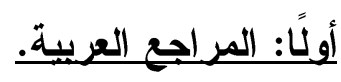

أحمد أمين سليم: در اسات في تاريخ وحضارة مصر و الثرق الأدنى القديه،

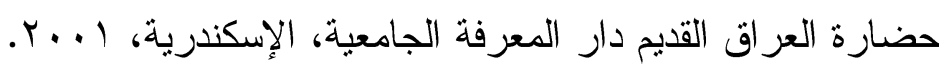

أ-د- جرنى: الحيثيون، ترجمة، محمد عبد القادر محمد، مر اجعة، فيصل الو ائلى،

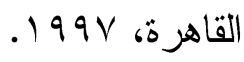

ختام عدنان على: آلهة بابل العظيمة آنو ونركال، مشروع اشوربانيبال للثقافة V V

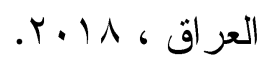

شيماء صلاح أحمد: الآلهة لاما عند العر اقيين القدماء، مجلة دراسات في الثاريخ

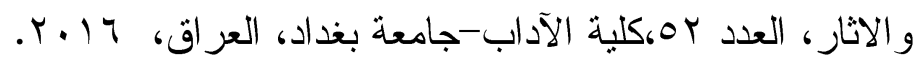

ناصر محمد مكاوى- عزيز محمد عزيز : عشتار ومدينة أربيل، مجلة دراسات

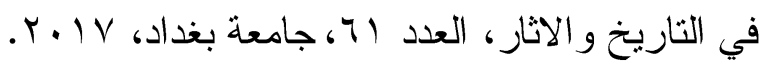

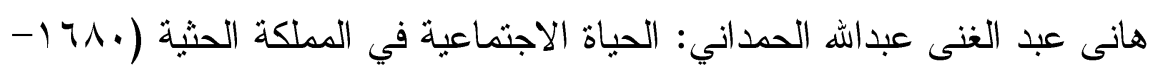

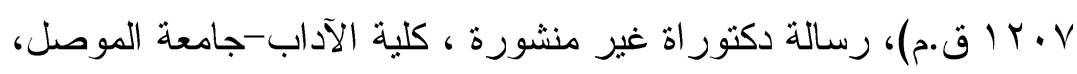

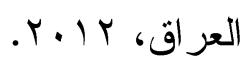

- Alexander, R., "Šaušga and the Hittite ivory from Megiddo, In. JNES, Vol.50, No. 3, 1991

- Allen, S., The Splintered Divine, A Study of Ištar, Baal, and Yahweh Divine Names and Divine Multiplicity in the Ancient Near East, Berlin, 2015

-Beckman,G., "my sun god" Reflections of Mesopotamian conceptions of kingship among the Hittite*, In, Ideologies as Intercultural phenomena, Editor. Panaino, A.(other), , Melammu Symposia 3. Milano, 2002. 


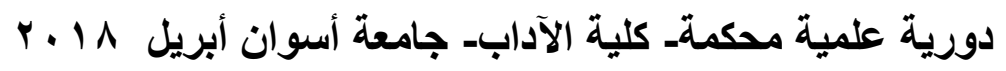

.-................, "Ištar of Nineveh reconsidered". In, JCS, vol. 50, 1998

-.................,"The religion of the Hittites". In, BA, Vol. 52, No. 2/ 3,1989 .

1982.

-Belmonte, J. (other).,"Thinking Hattusha: Astronomy and landscape in the Hittite lands". In, JHA, Vol. Xlii, 2011.

- Blasweiler, J., "The Tawananna and the royal succession", In. A paper at the 10th Hittitology Congress in Chicago, University of Chicago,2017.

-............, The bloodline of the Tawananna and the offering to the ancestors in the kingdom of Hatti, Netherlands, 2016.

-..........., The cult of the Kursa in the kingdom of Hattusa,the Illuyankamyth and the way to colchis, Netherlands, 2014.

- Bossert. H., “Meine sonne”, In.Or NS, Vol. 26 , 1957.

- Brison, O., " Aggressive goddesse, abusive men: gender role change in Near Eastern mythology", In., SMEA, vol. 49,2007.

- Bryce, T., The routledge handbook of the peoples and places ancient westrn Asia, the near wast from the early bronze age to the fall of the Persian empire, New York, 2009.

$-\ldots \ldots . . .$, R., The kingdom of Hittites, Oxford, 2005.

Life and society in the Hittite world, Oxford, 2002.

- Burney, C., Historical dictionaries of the Hittites, Oxford, 2004.

-Carol F. Justus, "Indo-Europeanization of Myth and Syntax in Anatolian Hittite:

Dating of Texts as an Index, JIES, vol. 11, 1983.

- Collins, B, J., The Hittites and ther world, Atlanta, 2007.

- Daniè le, M., "The royal Hittite title 'My Sun, and the Winged Sun Disk ». In: 38. ICANAS, Religion, vol. 1, International Congress of 
Asian and North African Studies, Ankara 2007, Atatürk Kultür, Dil Ve Tarih Yüsek Kuramu Yaninlari 3/1, Ed. Zeki Dilek et al., Ankara.

- Danmanvilie, J., “ Iconographie d'Ištar-šaušga en Anatolie ancienne, In. RA, vol.56, No.1, 1962.

- David, S., "Transformation of a goddess: Ishtar- Astarte - Aphrodite". In, OBO, Vol. 263, 2014.

- Dongen, E., "The Hittite " Song of going forth" (CTH344) : A reconsideration of the narrative". In, WdO, Bd. 42, H. 1, 2012.

- Forsgren, M., "The divine appearance of Harn", current Swedish archeology, vol.18, 2010.

- Ghirshman, R., Iran from the earliest times to the Islami conquest,Translated from the French by Miss Margared MumRankin, (Pelican books), London, 1978.

- Giorgadez, G,G.,"The Hittite kingdom", In.Early Antiquity, Edit by Diakonoff, I. Chicago and London, 1991.

- Glatz, C., (other)., "The historical geography of north-central Anatolia in the Hittite period: texts and archaeology in concexrt", In, AS, Vol.59, 2009.

- Gonnet, H., "Gonnet née Bagana Hatice. La titulature royale hittite au IIe millénaire av. J.C,EPHE, Vol.80-81, 1971.

- Gurney, O., Some aspects of Hittite religion, Oxford, 1977.

- Güerbock, H., "An addition to the prayer of Muršili to the sungoddess and its implication", AS, Vol.30, 1980

-.............. "The composition of Hittite prayers to the sun", in, JAOS, vol. 78, No.4, 1958.

- Haas, V., Geschichte der Hethitischen religion, New York, 1994.

- Hoffner, H., The royal cult in Hatti, 2006.

," Symbols for masculinity and feminity: Their use in ancient near eastern sympathetic magic rituals", JBL,Vol. 85, No. 3, 1966. 


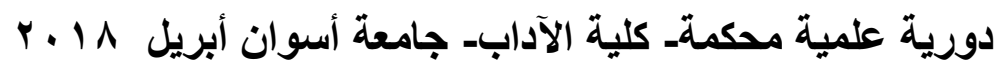

-.............., Hittite Myths, Atlanta, 1990.

- ............, The laws of the Hittite, PhD. Barndies university, 1963

- Jones, L., Encyclopedia of religion, vol.6, 2005.

- Jordan, M., Dictionary of gods and goddesses, New York, 2014

- Karasu, C., "Why did the Hittites have a thousand deities?",In. Hittite studies in honor of Harry A.Hoffner JR. On the occasion of 65Th birthday.Edited by Beckman.G., (others),Winona, Indiana, 2003>

- Kuhrt, A.,'Women and War", In. NIN, Vol.2. 2001.

- Laroche, E., "Panthéon national et panthéons locaux chez les Hourrites", In. Or NS, Vol.45,1976

" Hattic Deities and their Epithets", JCS, Vol. 1, No. 3, 1947.

- Leeming, D.,Creation myths of the world: An Encyclopedia. Vol.1, parts I-II, Oxford, 2010.

- Leick, G., A dictionary of ancient near eastern mythology, London\&New York, 1991.

- Lerner, G., The creation of patriarchy, Oxford, 1986.

- Marinatos, N., "The minoanharem: The role of eminent women and the knossos frescoes*", Dialogues d,histoire ancienne, Vol.152,1989 .

47-Macqueen, J., "Hattian mythology and Hittite monarchy, In, AS, vol.9,1959.

- McGrath, S., "The hidden Sun", In. Drawing own the Sun : Rekindle the Magick of the Solar Goddesses, Edit by Woodfield, S.,Woodbury, Minnesota, 2014.

- McMahon, G., The Hittite state cult of the tutelary deities, Assyriological Studies, No.25, Chicago. 1991

- Motz, L., The faces of the goddess, Oxford, 1997.

-Morritt, R, D.,Stones that speak,Cambridge, 2010. 
- Neu, E., Der Anitta-text(studien zu den Bogazkoy-Texten), Band.18, Otto Harrassowitz. Wiesbaden, 1974.

-Onurlu, S., Symbolspace and meaning in the Hittite architecture, Middle east technical university, Ankara, 2004.

- Oppenheim, M., "Imamkulu, ein neues subaräisches Denkmal aus der Hettiterzeit in Kleinasien”, In. AFO, 11. 1936-1937.

- Pritchard, J. B., Ancient Near Eastern texts, Relating to the Old Testament, Princeton. New Jersey,1969

-Ryst, A. F., An investigation into the extensive religious and political elements that impacted on the reigns of Hattušili III, Puduhepa and their son,Tudhaliya IV (ca1267-1228 BCE), university of south Africa, 2016.

- Sánchez, D, (others)., Mediterráneos: An interdisciplinary approach to the cultures of the Mediterranean sea, Cambridge, 2013.

-Singer, I, (Other)., Hittite prayers, vol.11, Atlanta, Georgia, 2002.

- Stricklin, D., Hittite culture and mythology I, 2015.

-Taracha, P., Religions of second millennium Anatolia, Wiesbaden, 2009.

- Tatišvili, I., "Transformations of the relationship between Hittite Kings and deities", published in the Acts of the IXth International Congress of Hittitology,Çorum, 2014

- Winter, W, other., Reconstructing Languages and Cultures, New York, 1992.

- Yigit, T., "The Political and Cultural Meanings of the Hittite Empire Period Rock Monuments”, In: AJH, Vol.2, No.1, 2016.

\section{ثَالثًا: المواقِع الاككترونبة.}

http://www.transanatolie.com/English/Turkey/Anatolia/Ancient\%20 $>$ Cities/Corum/Hattusas/yazilikaya.htm

-http://www.hittitemonuments.com/fraktin 


\begin{tabular}{|l|l|}
\hline AJH & Athens Journal of History. \\
\hline AFO & Archiv für Orientforschung \\
\hline Anst & Anatolian studies. \\
\hline BA & The BiblicalArchaeologist . \\
\hline DHA & Dialogues d,histoire ancienne \\
\hline EPHE & Annuaires de l'École pratique des hautes études. \\
\hline JANES & Journal of the Ancient Near Eastern Society. \\
\hline JAOS & Journal of the American Oriental Society, New Haven. \\
\hline JBL & Journal of Biblical Literature. \\
\hline JCS & Journal of Cuneiform Studies, New Haven. \\
\hline JIES & Journal o f Indo-European Studies. \\
\hline JNES & Journal of Near Eastern studies, Chicago. \\
\hline NIN & Journal of GENDER STUDIES IN ANTIQUITY. \\
\hline OBO & Orbis biblicus et orientalis. \\
\hline Or NS & Orientalia, NOVA SERIES, Published by: Gregorian Biblical Press. \\
\hline RA & Revue d'Assyriologie et d'archéologie orientale. \\
\hline SMEA & studi Micenei ed Egeo-Anatoloci. \\
\hline WdO & Die Welt des Orients- Jornal. \\
\hline
\end{tabular}

